Article

\title{
Design, Synthesis and Evaluation of Indene Derivatives as Retinoic Acid Receptor $\alpha$ Agonists
}

\author{
Xianghong Guan, Peihua Luo, Qiaojun He, Yongzhou Hu and Huazhou Ying * \\ ZJU-ENS Joint Laboratory of Medicinal Chemistry, College of Pharmaceutical Sciences, \\ Zhejiang University, Hangzhou 310058, China; guanx082@umn.edu (X.G.); peihualuo@zju.edu.cn (P.L.); \\ qiaojunhe@zju.edu.cn (Q.H.); huyz@zju.edu.cn (Y.H.) \\ * Correspondence: yybb@zju.edu.cn; Tel./Fax: +86-571-8820-8445
}

Academic Editor: Santosh K. Katiyar

Received: 4 November 2016; Accepted: 24 December 2016; Published: 27 December 2016

\begin{abstract}
A series of novel indene-derived retinoic acid receptor $\alpha(\operatorname{RAR} \alpha)$ agonists have been designed and synthesized. The use of receptor binding, cell proliferation and cell differentiation assays demonstrated that most of these compounds exhibited moderate RAR $\alpha$ binding activity and potent antiproliferative activity. In particular, 4-((3-isopropoxy-2,3-dihydro- $1 H$-inden-5-yl)-carbamoyl) benzoic acid (36d), which showed a moderate binding affinity, exhibited a great potential to induce the differentiation of NB4 cells $(68.88 \%$ at $5 \mu \mathrm{M})$. Importantly, our work established indene as a promising skeleton for the development of novel RAR $\alpha$ agonists.
\end{abstract}

Keywords: retinoic acid receptor; agonist; all-trans-retinoic acid derivative; indene; structure and activity relationship

\section{Introduction}

The retinoid signal is mediated in target cells through retinoic acid receptors (RAR) and retinoid $X$ receptors (RXR), both of which are members of the nuclear receptor superfamily. RARs are ligand-dependent transcription factors that act as RAR-RXR heterodimers to modulate gene transcription and thereby regulate a range of metabolic, endocrine and immunologic disorders $[1,2]$. There are three distinct isoforms RAR $(\alpha,-\beta$ and $-\gamma)$, among which RAR $\alpha$ is known to play a pivotal role in the control of cellular differentiation and apoptosis, and is therefore an important drug target for cancer therapy and prevention [3]. The natural ligand of RAR $\alpha$, all-trans-retinoic acid (ATRA), has been used to effectively treat acute promyelocytic leukaemia (APL) for nearly thirty years [4]. However, this therapy has its limitations which mainly lie in the structure of ATRA. Due to the presence of conjugated double bonds, ATRA easily undergoes oxidation and/or isomerization in the presence of oxidants, light or excessive heat [5]. To improve the stability, a large number of derivatives have been developed by fusing an aromatic ring in both its hydrophobic and hydrophilic regions to constrain the polyene side chain. The study of the relationships between structure and activity (SAR) has established the structure template of ATRA derivatives as a hydrophobic region and a polar region connected via a linker (Figure 1) [6-8]. Further SAR has revealed that the nature of the linker is crucial for the compounds to attain RAR-isotype selectivity and that the amide linker group is a key structural feature for RAR $\alpha$-specificity, presumably due to a favorable hydrogen-bonding interaction between the amide group of the ligand and the hydroxyl group of serine 232 residue present in the ligand binding pocket of $\operatorname{RAR} \alpha[9,10]$.

Among all the ATRA derivatives, AM80 (Figure 1) is a typical representative approved for therapy in 2005. AM80 can successfully induce complete remission in APL patients for whom ATRA therapy has failed [11-13]. This implies the great potential of synthetic RAR $\alpha$ agonists in the treatment of APL and has fostered the search for new classes of compounds with improved pharmacologic activities. 
<smiles>CC1=C(/C=C/C(C)=C/C=C/C(C)=C/C(=O)O)C(C)(C)CCC1</smiles><smiles>CC1(C)CCC(C)(C)c2c1cc(C(=O)Nc1cc(F)c(C(=O)O)c(F)c1)c(O)c2Cl</smiles>

AGN $195183(3)$

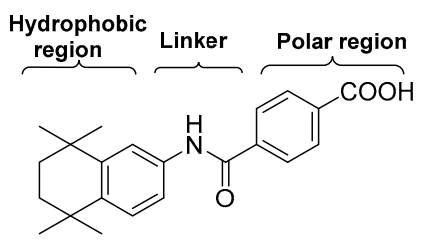

AM80 (2)<smiles>CCOC(=O)c1ccc(C#Cc2ccc3c(c2)C(C)(C)CCS3)nc1</smiles>

Figure 1. Chemical structures of ATRA (1) and representative aromatic RA derivatives (2-4).

To date, most of the developed ATRA derivatives contain a tri-/tetra-methylated six-membered rigid ring in their hydrophobic region. Since it has been reported that the size of the hydrophobic part of the ligands can significantly affect the activity [10], we were interested in studying the impact of a smaller ring system on the activity of derivatives by replacing the hydrophobic part of AM80 with mono-/di- substituted indene derivatives. Specifically, compound 5 was designed by incorporating small alkoxyl or alkyl groups into the indane structure. Keeping the planar configuration of indene by retaining the double bond or the incorporation of a ketone group yielded compounds 6 and 7 . Di-substitution of indane with both alkoxyl and alkyl groups gave compounds 8 (Figure 2).<smiles>[R][C@H](OCC)OC(OCC)OCC</smiles>

5<smiles>[R]C1Cc2ccc(NC(=O)c3ccc(C(=O)O)cc3)cc2C1=O</smiles>

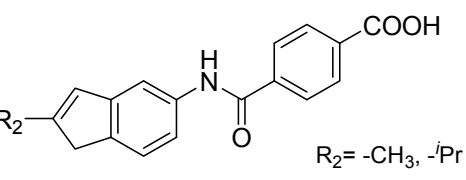

6

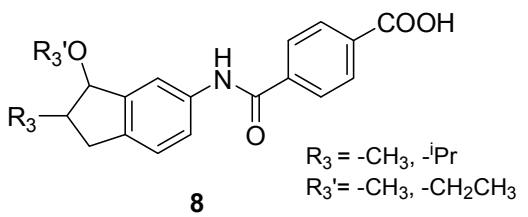

Figure 2. Chemical structures of indene derived compound series 6-8.

\section{Chemistry}

Synthesis of indene derivatives $36 \mathbf{a}-\mathbf{p}$ was conducted via procedures reported for the preparation of AM80 with some modifications. Detailed syntheses are shown in Scheme 1. Nitration of commercial available 9 with $\mathrm{KNO}_{3}$ and $\mathrm{H}_{2} \mathrm{SO}_{4}$ gave 10, whose carbonyl group was then reduced by $\mathrm{NaBH}_{4}$ to yield 11. Elimination of $\mathrm{H}_{2} \mathrm{O}$ from 11 gave 12, which could either be reduced to 13 or transformed into 16 [14,15]. Etherification of 16 with alkyl halides in the presence of $\mathrm{KOH}$ produced 17a and 17b. Compound 11 could also be alkylated with appropriate halogenoalkane (MeI, EtI, 2-bromo-propane or 1-bromobutane) to afford 14a-d. In another synthetic route, 9 was reacted with paraformaldehyde/acetone to give 19a and $19 b$, which were reduced to yield $20 a$ and $20 b$. Subsequent nitration of $20 a$ and $20 b$ and reduction of the carbonyl group gave 22a and $\mathbf{2 2} \mathbf{b}$. Compounds $\mathbf{2 3 a}$ and $\mathbf{2 3 b}$ could be obtained by elimination reaction of 22a and 22b, while coupling of 22a, 22b with trimethyl orthoformate or triethyl orthoformate in the presence of $\mathrm{BiCl}_{3}$ yielded $27 \mathrm{a}, \mathbf{2 8 a}$ and $\mathbf{2 7 b}, \mathbf{2 8 b}$, respectively. Reduction of the nitro group in 14a-d, 17a, 17b, 21a, 21b, 23a, 23b, 27a, 27b and 28a, 28b then yielded the hydrophobic moieties 15a-d, 18a, 18b, 26a, 26b, 24, 25a, 25b, 29a, 29b and 30a, 30b [16]. 


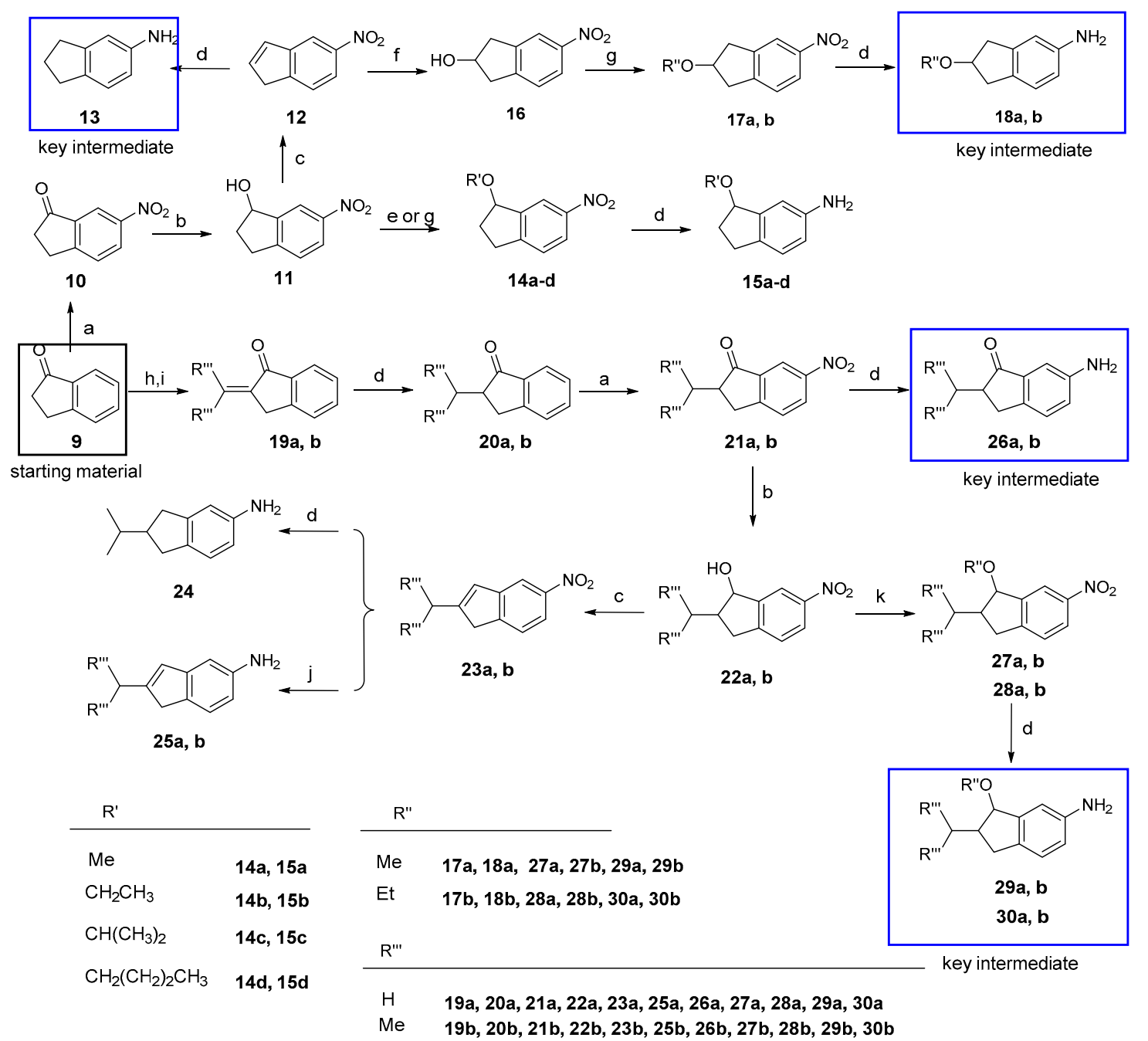

Scheme 1. The synthetic route of 13, 18a, 18b, 26a, 26b, 29a, 29b, 30a, 30b. Reagents and conditions: (a) $\mathrm{KNO}_{3}, \mathrm{H}_{2} \mathrm{SO}_{4}, 0^{\circ} \mathrm{C}, 4 \mathrm{~h}$; (b) $\mathrm{NaBH}_{4}, \mathrm{MeOH} / \mathrm{THF}=2 / 1,1 \mathrm{~h}$; (c) $p$-toluenesulfonamide, PhMe, reflux, $2 \mathrm{~h}$; (d) $\mathrm{H}_{2}, 10 \% \mathrm{Pd} / \mathrm{C}$, EtOAc, r.t., overnight; (e) MeI or EtI, MeONa, THF, r.t., 12 h; (f) (i) diborane, THF, r.t., $2 \mathrm{~h}$; (ii) $30 \% \mathrm{H}_{2} \mathrm{O}_{2}, 30 \% \mathrm{KOH}$ aq, r.t., $1 \mathrm{~h}$; (g) 2-bromo-propane or 1-bromobutane $\mathrm{HgO} / \mathrm{HBF}_{4}$, $\mathrm{CH}_{2} \mathrm{Cl}_{2}$, r.t., 2 h; (h) paraformaldehyde, $\mathrm{AcOH}$, morpholine, reflux, 2 h; (i) acetone, $\mathrm{NaOH}$, r.t., 4 h; (j) Fe, $\mathrm{AcOH}, \mathrm{EtOH}$, reflux, $2 \mathrm{~h}$; (k) methyl orthoformate or triethoxy orthoformate, $\mathrm{BiCl}_{3}, \mathrm{CH}_{2} \mathrm{Cl}_{2}$, r.t., 7 h.

The hydrophilic segment 34 was prepared from terephthalic acid (31) after esterification and hydrolysis, followed by chlorination. Coupling of 34 with the hydrophobic part yielded 35a-p which were then hydrolyzed to give the target ligands $36 \mathbf{a}-\mathbf{p}$ (Scheme 2).

\section{Results and Discussion}

\subsection{RARx Binding Affinity}

The obtained target compounds were tested for their binding affinities to RAR $\alpha$ using a time resolved fluorescence resonance energy transfer (TR-FRET) assay with AM80 as the positive control. As shown in Table 1, compound 36a which bears no substituents exhibits modest RAR $\alpha$ binding affinity, implying the feasibility of the indene skeleton as a promising platform for novel RAR $\alpha$ agonists. With $\mathbf{3 6 b}-\mathbf{3 6 g}$ being less potent than $\mathbf{3 6 a}$, it seems that an alkoxyl group is not welcome, especially at the 2-position. 

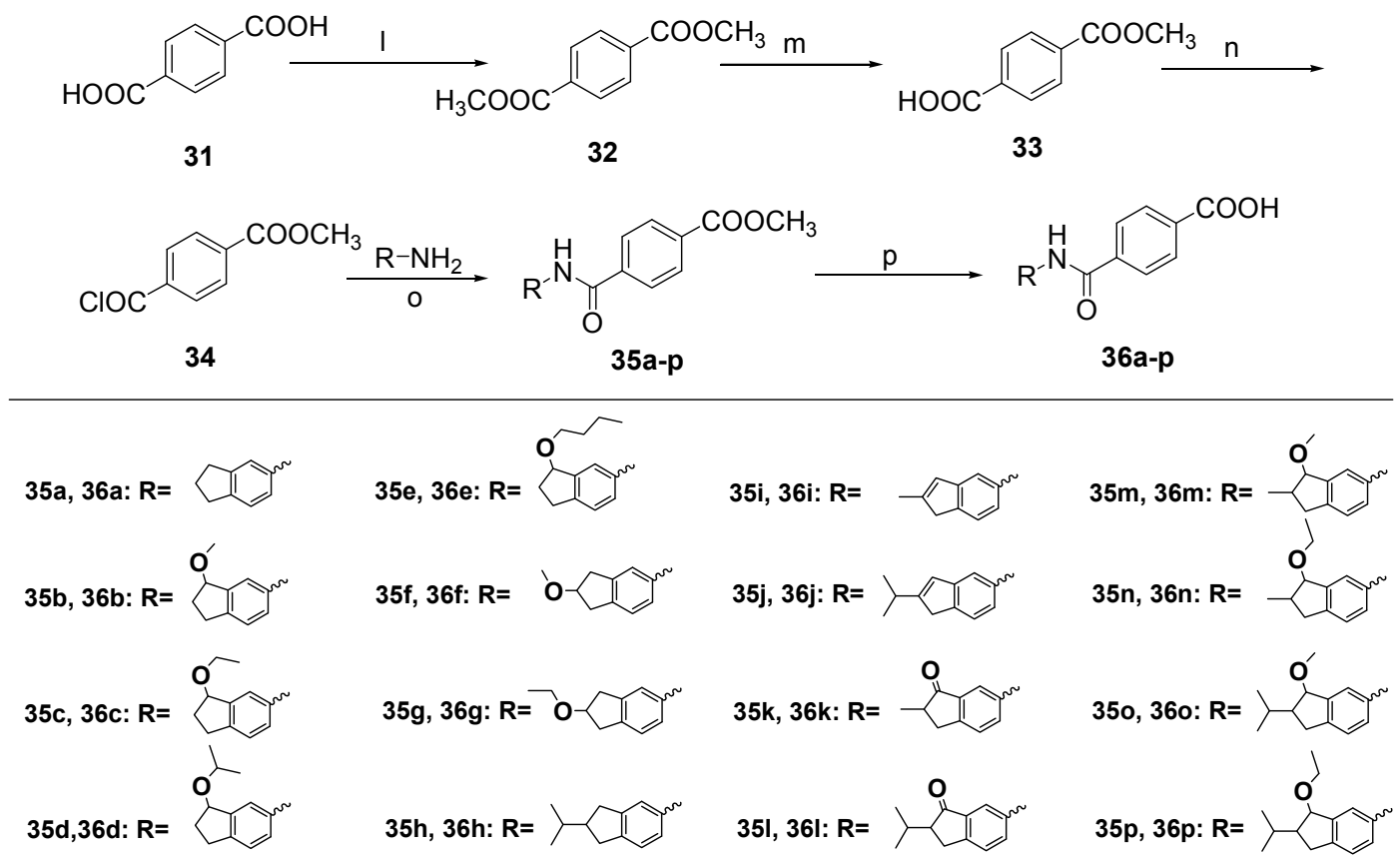

Scheme 2. The synthetic route of 36a-36p. Reagents and conditions: (l) $\mathrm{MeOH}, \mathrm{SOCl}_{2}, \mathrm{r.t.}, 12 \mathrm{~h}$; (m) $\mathrm{KOH}$, $\mathrm{MeOH}$, ether, $\mathrm{H}_{2} \mathrm{O}$, r.t., 24 h; (n) $\mathrm{SOCl}_{2}$, reflux, 24 h; (o) amine fragments, $\mathrm{Py}, \mathrm{CH}_{2} \mathrm{Cl}_{2}$, r.t., 7 h; (p) $0.5 \%$ $\mathrm{LiOH}$ aq, $\mathrm{MeOH}$, r.t., 48 h.

Table 1. RAR $\alpha$ binding affinity of compounds $36 a-36 p$.<smiles>[R]C1Cc2ccc(NC(=O)c3ccc(C(=O)O)cc3)cc2C1[R]</smiles>

$36 a-h, 36 m-p$<smiles>[R]C1=Cc2cc(NC(=O)c3ccc(C(=O)O)cc3)ccc2C1</smiles>

$36 i-j$<smiles>[R3]C1Cc2ccc(NC(=O)c3ccc(C(=O)O)cc3)cc2C1=O</smiles>

$36 k-I$

\begin{tabular}{|c|c|c|c|c|c|}
\hline Compounds & $\mathbf{R}_{1}$ & $\mathbf{R}_{\mathbf{1}}^{\prime}$ & $\mathbf{R}_{2}$ & $\mathbf{R}_{3}$ & $\mathrm{EC}_{50}(\mathrm{nM})$ \\
\hline AM80 & - & - & - & - & 0.170 \\
\hline $36 a$ & $\mathrm{H}$ & $\mathrm{H}$ & - & - & 12.13 \\
\hline $36 b$ & $-\mathrm{OCH}_{3}$ & $\mathrm{H}$ & - & - & 129.6 \\
\hline $36 c$ & $-\mathrm{OCH}_{2} \mathrm{CH}_{3}$ & $\mathrm{H}$ & - & - & 311.5 \\
\hline $36 d$ & $-\mathrm{OCH}\left(\mathrm{CH}_{3}\right)_{2}$ & $\mathrm{H}$ & - & - & 24.25 \\
\hline $36 e$ & $-\mathrm{O}\left(\mathrm{CH}_{2}\right)_{3} \mathrm{CH}_{3}$ & $\mathrm{H}$ & - & - & 14.88 \\
\hline $36 f$ & $\mathrm{H}$ & $-\mathrm{OCH}_{3}$ & - & - & $>1000$ \\
\hline $36 \mathrm{~g}$ & $\mathrm{H}$ & $-\mathrm{OCH}_{2} \mathrm{CH}_{3}$ & - & - & $>1000$ \\
\hline $36 \mathrm{~h}$ & $\mathrm{H}$ & $-\mathrm{CH}\left(\mathrm{CH}_{3}\right)_{2}$ & - & - & 42.96 \\
\hline $36 \mathbf{i}$ & - & - & $-\mathrm{CH}_{3}$ & - & 14.08 \\
\hline $36 \mathbf{j}$ & - & - & $-\mathrm{CH}\left(\mathrm{CH}_{3}\right)_{2}$ & - & 3.529 \\
\hline $36 k$ & - & - & - & $-\mathrm{CH}_{3}$ & 1375 \\
\hline 361 & - & - & - & $-\mathrm{CH}\left(\mathrm{CH}_{3}\right)_{2}$ & 4.677 \\
\hline $36 \mathrm{~m}$ & $-\mathrm{OCH}_{3}$ & $-\mathrm{CH}_{3}$ & - & - & 291.9 \\
\hline $36 n$ & $-\mathrm{OCH}_{2} \mathrm{CH}_{3}$ & $-\mathrm{CH}_{3}$ & - & - & 146.1 \\
\hline 360 & $-\mathrm{OCH}_{3}$ & $-\mathrm{CH}\left(\mathrm{CH}_{3}\right)_{2}$ & - & - & 3.933 \\
\hline $36 p$ & $-\mathrm{OCH}_{2} \mathrm{CH}_{3}$ & $-\mathrm{CH}\left(\mathrm{CH}_{3}\right)_{2}$ & - & - & 9.031 \\
\hline
\end{tabular}

Furthermore, the extension of the $\pi$ system by the retention of the indene double bond or the incorporation of a ketone group at the 1-position seems to be favorable, with $\mathbf{3 6 j}$ and $\mathbf{3 6 1}$ being more potent than their more saturated counterpart 36h. Interestingly, although an alkoxy-substituent alone is not well tolerated, it contributes to the binding affinity when coexisting with an isopropyl group, which is illustrated by comparison of the results of $360,36 p$ with those of $36 \mathbf{b}$ and $36 \mathrm{c}$. 


\subsection{Cell Proliferation Inhibitory Assay}

Human promyelocytic leukemia cell lines HL60 and NB4 were employed to determine the effects of the derivatives on cell proliferation [17]. As shown in Table 2, these two cell lines responded quite differently to the tested compounds. Compounds $36 \mathbf{b}-\mathbf{c}$ with small aliphatic ether chains at the 1-position are more potent than 36d-e with larger ether side chains in HL60 cells, while the results in NB4 cells are the contrary. Alkoxy-substitution at the 2-position (i.e., compounds 36f, 36g) harmed the cell proliferation inhibitory activity of the compounds in both cell lines while the isopropyl group at the same position (compound $\mathbf{3 6 h}$ ) is favourable. The extension of the $\pi$ system by an alkenyl bond or a ketone group, as in $\mathbf{3 6} \mathbf{j}-\mathbf{1}$, didn't affect the compounds' inhibitory activity in HL60 cells but nulified their activity in NB4 cells. The indene ring tolerates the dual-introduction of a small alkoxyl and an alkyl group at 1- and 2-position, respectively, to retain the antiproliferative activity in HL60 cells. The results of the dual-substituted compounds in the NB4 cells line are a little complicated, with 36n and 36p bearing an ethoxyl group at the 1-position showing moderate activity and 36m and 36o with a methoxyl group at the same position being almost inactive.

Table 2. Results of cell proliferation inhibitory assay using HL60 and NB4 cells.<smiles>[R]C1=Cc2cc(NC(=O)c3ccc(C(=O)O)cc3)ccc2C1</smiles>

36a-h, 36m-p<smiles>[R3]C1Cc2ccc(NC(=O)c3ccc(C(=O)O)cc3)cc2C1=O</smiles>

$36 k-1$

\begin{tabular}{|c|c|c|c|c|c|c|}
\hline \multirow{2}{*}{ Compounds } & \multirow{2}{*}{$\mathbf{R}_{\mathbf{1}}$} & \multirow{2}{*}{$\mathbf{R}_{\mathbf{1}}{ }^{\prime}$} & \multirow{2}{*}{$\mathbf{R}_{2}$} & \multirow{2}{*}{$\mathbf{R}_{3}$} & \multicolumn{2}{|c|}{$\mathrm{IC}_{50}(\mu \mathrm{M})$} \\
\hline & & & & & HL60 & NB4 \\
\hline AM80 & - & - & - & - & 0.170 & 13.28 \\
\hline $36 a$ & $\mathrm{H}$ & $\mathrm{H}$ & - & - & $>50$ & 6.97 \\
\hline $36 \mathrm{~b}$ & $-\mathrm{OCH}_{3}$ & $\mathrm{H}$ & - & - & 0.13 & 35.43 \\
\hline $36 c$ & $-\mathrm{OCH}_{2} \mathrm{CH}_{3}$ & $\mathrm{H}$ & - & - & 0.25 & $>50$ \\
\hline $36 \mathrm{~d}$ & $-\mathrm{OCH}\left(\mathrm{CH}_{3}\right)_{2}$ & $\mathrm{H}$ & - & - & $>50$ & 1.86 \\
\hline $36 \mathrm{e}$ & $-\mathrm{O}\left(\mathrm{CH}_{2}\right)_{3} \mathrm{CH}_{3}$ & $\mathrm{H}$ & - & - & $>50$ & 4.09 \\
\hline $36 f$ & $\mathrm{H}$ & $-\mathrm{OCH}_{3}$ & - & - & $>50$ & $>50$ \\
\hline $36 \mathrm{~g}$ & $\mathrm{H}$ & $-\mathrm{OCH}_{2} \mathrm{CH}_{3}$ & - & - & $>50$ & 21.99 \\
\hline $36 \mathrm{~h}$ & $\mathrm{H}$ & $-\mathrm{CH}\left(\mathrm{CH}_{3}\right)_{2}$ & - & - & 0.91 & 2.61 \\
\hline $36 \mathbf{i}$ & - & - & $-\mathrm{CH}_{3}$ & - & $>50$ & $>50$ \\
\hline $36 \mathbf{j}$ & - & - & $-\mathrm{CH}\left(\mathrm{CH}_{3}\right)_{2}$ & - & 2.37 & $>50$ \\
\hline $36 k$ & - & - & - & $-\mathrm{CH}_{3}$ & 2.66 & $>50$ \\
\hline 361 & - & - & - & $-\mathrm{CH}\left(\mathrm{CH}_{3}\right)_{2}$ & 2.11 & 36.90 \\
\hline $36 \mathrm{~m}$ & $-\mathrm{OCH}_{3}$ & $-\mathrm{CH}_{3}$ & - & - & 0.43 & $>50$ \\
\hline $36 n$ & $-\mathrm{OCH}_{2} \mathrm{CH}_{3}$ & $-\mathrm{CH}_{3}$ & - & - & 0.80 & 8.51 \\
\hline 360 & $-\mathrm{OCH}_{3}$ & $-\mathrm{CH}\left(\mathrm{CH}_{3}\right)_{2}$ & - & - & 2.35 & $>50$ \\
\hline $36 p$ & $-\mathrm{OCH}_{2} \mathrm{CH}_{3}$ & $-\mathrm{CH}\left(\mathrm{CH}_{3}\right)_{2}$ & - & - & 1.13 & 7.56 \\
\hline
\end{tabular}

\subsection{Cell Differentiation Assay Using HL60 and NB4}

The effects of $\mathbf{3 6 a}-\mathbf{g}$ on the differentiation of HL60 and NB4 cells were then assessed. FACS analysis of the granulocyte differentiation marker CD11b revealed that $36 \mathbf{d}$ and 36e, which show high binding affinity to $\operatorname{RAR} \alpha(14.88 \sim 24.25 \mathrm{nM})$ and potent proliferation inhibitory activity in NB4 cells $(1.86 \sim 4.09 \mu \mathrm{M})$, have the greatest potential to induce NB4 cell maturation (Table 3), which is in correspondence with the molecular basis of APL [18]. 
Table 3. Cell differentiation potential of compounds 36a-g.

\begin{tabular}{|c|c|c|c|c|}
\hline \multicolumn{5}{|c|}{$36 a-g$} \\
\hline \multirow{2}{*}{ Compounds } & \multirow{2}{*}{$\mathbf{R}_{1}$} & \multirow{2}{*}{$\mathbf{R}_{\mathbf{1}}^{\prime}$} & \multicolumn{2}{|c|}{ CD11b (\%) ${ }^{a}$} \\
\hline & & & HL60 & NB4 \\
\hline AM80 & - & - & $4.59(10 \mu \mathrm{M})$ & $94.93(10 \mu \mathrm{M})$ \\
\hline $36 a$ & $\mathrm{H}$ & $\mathrm{H}$ & $1.13(50 \mu \mathrm{M})$ & $0.97(5 \mu \mathrm{M})$ \\
\hline $36 \mathrm{~b}$ & $-\mathrm{OCH}_{3}$ & $\mathrm{H}$ & nd & nd \\
\hline $36 c$ & $-\mathrm{OCH}_{2} \mathrm{CH}_{3}$ & $\mathrm{H}$ & nd & nd \\
\hline $36 d$ & $-\mathrm{OCH}\left(\mathrm{CH}_{3}\right)_{2}$ & $\mathrm{H}$ & $3.77(50 \mu \mathrm{M})$ & $68.88(5 \mu \mathrm{M})$ \\
\hline $36 e$ & $-\mathrm{O}\left(\mathrm{CH}_{2}\right)_{3} \mathrm{CH}_{3}$ & $\mathrm{H}$ & $2.87(50 \mu \mathrm{M})$ & $15.42(5 \mu \mathrm{M})$ \\
\hline $36 f$ & $\mathrm{H}$ & $-\mathrm{OCH}_{3}$ & nd & nd \\
\hline $36 \mathrm{~g}$ & $\mathrm{H}$ & $-\mathrm{OCH}_{2} \mathrm{CH}_{3}$ & $5.82(50 \mu \mathrm{M})$ & $0.49(20 \mu \mathrm{M})$ \\
\hline
\end{tabular}

\section{Materials and Methods}

\subsection{General Information}

Unless otherwise noted, all reagents were purchased from commercial suppliers and used without further purification. Anhydrous THF was distilled from Na prior to use. Reactions were monitored by thin layer chromatography using TLC Silica gel $60 \mathrm{~F}_{254}$ supplied by Qingdao Puke Separation Material Corporation (Qingdao, China). Silica gel for column chromatography was 200-300 mesh and was supplied by Qingdao Marine Chemical Factory (Qingdao, China). Characterization of intermediates and final compounds was done using NMR spectroscopy and mass spectrometry. ${ }^{1} \mathrm{H}-\mathrm{NMR}$ spectra (500 MHz) were determined in $\mathrm{CDCl}_{3}$ on an Advance III $\mathrm{MHz}$ spectrometer (Bruker, Bremen, Germany) with TMS as internal standard. Chemical shifts are expressed in parts per million (ppm) and coupling constants in Hz. Mass spectra (ESI-MS) were recorded on an Esquire-LC-00075 spectrometer (Bruker, Bremen, Germany). HRMS were recorded on a 6224 TOF LC/MS spectrometer (Agilent, Santa Clara, CA, USA). Purity was confirmed on a Agilent 1100 series HPLC system equipped with a C18 column (Eclipse XDB-C18, $5 \mu \mathrm{m}, 4.6 \times 250 \mathrm{~mm}$ ) eluted in gradient mode with $\mathrm{CH}_{3} \mathrm{CN}$ in $\mathrm{H}_{2} \mathrm{O}$ (from $10 \%$ to 95\%). Melting points were measured with a B-540 melting-point apparatus (Büchi, Flawil, St. Gallen, Switzerland) and are uncorrected.

\subsection{Chemistry}

6-Nitro-2,3-dihydro-1H-inden-1-one (10). To a solution of 2,3-dihydro-1H-inden-1-one (9, $1.32 \mathrm{~g}$, $10.0 \mathrm{mmol})$ in concentrated sulfuric acid $(10 \mathrm{~mL}), \mathrm{KNO}_{3}(1.21 \mathrm{~g}, 12.0 \mathrm{mmol})$ in concentrated sulfuric acid $(10 \mathrm{~mL})$ was added dropwise at $-5{ }^{\circ} \mathrm{C}$ in $30 \mathrm{~min}$. The mixture was stirred at $-5{ }^{\circ} \mathrm{C}$ for $4 \mathrm{~h}$. After adding ice water slowly, the mixture was partitioned between water and $\mathrm{CH}_{2} \mathrm{Cl}_{2}$. The organic layer was washed with a saturated aqueous solution of $\mathrm{NaHCO}_{3}$ and brine, dried over anhydrous $\mathrm{Na}_{2} \mathrm{SO}_{4}$, and concentrated under vacuum. The residue was purified by column chromatography on silica gel (eluent: hexane/EtOAc $=7 / 1)$ to give $10(1.10 \mathrm{~g}, 62 \%)$ as a beige solid. m.p. $71 \sim 74{ }^{\circ} \mathrm{C}$; ${ }^{1} \mathrm{H}-\mathrm{NMR}: \delta 8.59(\mathrm{~d}, J=1.9 \mathrm{~Hz}, 1 \mathrm{H}), 8.47(\mathrm{dd}, J=8.4,2.2 \mathrm{~Hz}, 1 \mathrm{H}), 7.68(\mathrm{t}, J=8.4 \mathrm{~Hz}, 1 \mathrm{H}), 3.33-3.25(\mathrm{~m}$, 2H), 2.89-2.78 (m, 2H); ESI-MS: $m / z[\mathrm{M}+\mathrm{H}]^{+} 178$.

6-Nitro-2,3-dihydro-1H-inden-1-ol (11). To a solution of $\mathbf{1 0}(1.77 \mathrm{~g}, 10.0 \mathrm{mmol})$ in a mixed solution of $\mathrm{MeOH} / \mathrm{THF}(2: 1,20 \mathrm{~mL}), \mathrm{NaBH}_{4}(1.52 \mathrm{~g}, 40.0 \mathrm{mmol})$ was added in portions. The mixture was stirred at room temperature for one hour. After the addition of water $(40 \mathrm{~mL})$, the mixture was partitioned between water and EtOAc. The organic layer was washed with a saturated aqueous brine, dried 
over anhydrous $\mathrm{Na}_{2} \mathrm{SO}_{4}$, and concentrated under vacuum. The residue was purified by column chromatography on silica gel (eluent: hexane/EtOAc $=2 / 1)$ to give $\mathbf{1 1}(1.64 \mathrm{~g}, 92 \%)$ as a white solid. m.p. $74 \sim 77^{\circ} \mathrm{C} ;{ }^{1} \mathrm{H}-\mathrm{NMR}: \delta 8.26(\mathrm{~d}, J=1.8 \mathrm{~Hz}, 1 \mathrm{H}), 8.15(\mathrm{dd}, J=8.3,2.1 \mathrm{~Hz}, 1 \mathrm{H}), 7.38(\mathrm{~d}, J=8.3 \mathrm{~Hz}, 1 \mathrm{H})$, $5.32(\mathrm{t}, J=6.2 \mathrm{~Hz}, 1 \mathrm{H}), 3.14(\mathrm{~m}, 1 \mathrm{H}), 2.98-2.85(\mathrm{~m}, 1 \mathrm{H}), 2.64-2.58(\mathrm{~m}, 1 \mathrm{H}), 2.09-1.97(\mathrm{~m}, 1 \mathrm{H})$; ESI-MS: $m / z[\mathrm{M}+\mathrm{H}]^{+} 180$.

5-Nitro-1H-indene (12). To a solution of $11(1.79 \mathrm{~g}, 10.0 \mathrm{mmol})$ in anhydrous toluene $(20 \mathrm{~mL}), \mathrm{TsOH}$ $(1.72 \mathrm{~g}, 10.0 \mathrm{mmol})$ was added at room temperature and the mixture was refluxed for $2 \mathrm{~h}$. The solvent was removed by distillation. After adding water $(40 \mathrm{~mL})$, the mixture was partitioned between water and EtOAc. The organic layer was washed with a saturated aqueous solution of $\mathrm{NaHCO}_{3}$ and brine, dried over anhydrous $\mathrm{Na}_{2} \mathrm{SO}_{4}$, and concentrated under vacuum. The residue was purified by column chromatography on silica gel (eluent: hexane/EtOAc $=10 / 1)$ to give $\mathbf{1 2}(1.38 \mathrm{~g}, 86 \%)$ as a white solid, m.p. $78 \sim 81^{\circ} \mathrm{C} ;{ }^{1} \mathrm{H}-\mathrm{NMR}: \delta 8.23(\mathrm{~d}, J=2.1 \mathrm{~Hz}, 1 \mathrm{H}), 8.11(\mathrm{dd}, J=8.2,2.1 \mathrm{~Hz}, 1 \mathrm{H}), 7.58(\mathrm{~d}, J=8.2 \mathrm{~Hz}, 1 \mathrm{H})$, $6.96(\mathrm{~d}, J=5.5 \mathrm{~Hz}, 1 \mathrm{H}), 6.76(\mathrm{dt}, J=5.4,1.9 \mathrm{~Hz}, 1 \mathrm{H}), 3.52(\mathrm{~s}, 2 \mathrm{H})$;ESI-MS: $m / z[\mathrm{M}+\mathrm{H}]^{+} 162$.

1-Methoxy-6-nitro-2,3-dihydro-1H-indene (14a). To a solution of $\mathbf{1 1}(90 \mathrm{mg}, 0.5 \mathrm{mmol})$ and $\mathrm{CH}_{3} \mathrm{I}(0.31 \mathrm{~mL}$, $5.0 \mathrm{mmol})$ in anhydrous THF $(2 \mathrm{~mL}), \mathrm{CH}_{3} \mathrm{ONa}(108 \mathrm{mg}, 2.0 \mathrm{mmol})$ was added at $0{ }^{\circ} \mathrm{C}$. The mixture was stirred at room temperature for $12 \mathrm{~h}$. After adding water $(20 \mathrm{~mL})$, the mixture was partitioned between water and EtOAc. The organic layer was washed with saturated brine, dried over anhydrous $\mathrm{Na}_{2} \mathrm{SO}_{4}$, and concentrated under vacuum. The residue was purified by column chromatography on silica gel (eluent: hexane $/ \mathrm{EtOAc}=30 / 1)$ to give $14 \mathrm{a}(39 \mathrm{mg}, 41 \%)$ as a pale yellow liquid. ${ }^{1} \mathrm{H}-\mathrm{NMR}$ : $\delta 8.26(\mathrm{~d}, J=2.0 \mathrm{~Hz}, 1 \mathrm{H}), 8.17(\mathrm{dd}, J=8.3,2.2 \mathrm{~Hz}, 1 \mathrm{H}), 7.40(\mathrm{~d}, J=8.3 \mathrm{~Hz}, 1 \mathrm{H}), 4.87(\mathrm{dd}, J=6.5,4.5 \mathrm{~Hz}$, $1 \mathrm{H}), 3.46(\mathrm{~s}, 3 \mathrm{H}), 3.20-3.13(\mathrm{~m}, 1 \mathrm{H}), 2.95-2.89(\mathrm{~m}, 1 \mathrm{H}), 2.52-2.40(\mathrm{~m}, 1 \mathrm{H}), 2.25-2.13(\mathrm{~m}, 1 \mathrm{H})$; ESI-MS: $m / z[\mathrm{M}+\mathrm{H}]^{+} 194$.

1-Ethoxy-6-nitro-2,3-dihydro-1H-indene (14b). The title compound was prepared (34 $\mathrm{mg}, 33 \%)$ as a pale yellow liquid from 11 and $\mathrm{CH}_{3} \mathrm{CH}_{2} \mathrm{I}$ in a similar method with that described for 14a. ${ }^{1} \mathrm{H}-\mathrm{NMR}$ : $\delta 8.24$ $(\mathrm{d}, J=2.1 \mathrm{~Hz}, 1 \mathrm{H}), 8.14(\mathrm{dd}, J=8.3,2.2 \mathrm{~Hz}, 1 \mathrm{H}), 7.37(\mathrm{~d}, J=8.3 \mathrm{~Hz}, 1 \mathrm{H}), 4.95(\mathrm{q}, J=6.5 \mathrm{~Hz}, 1 \mathrm{H}), 3.70-3.60$ $(\mathrm{m}, 2 \mathrm{H}), 3.18-3.12(\mathrm{~m}, 1 \mathrm{H}), 2.93-2.84(\mathrm{~m}, 1 \mathrm{H}), 2.50-2.43(\mathrm{~m}, 1 \mathrm{H}), 2.19-2.12(\mathrm{~m}, 1 \mathrm{H}), 1.27(\mathrm{t}, J=7.0 \mathrm{~Hz}$, 3H). ESI-MS: $m / z[\mathrm{M}+\mathrm{H}]^{+} 208$.

1-Isopropoxy-6-nitro-2,3-dihydro-1H-indene (14c). To a stirred solution of compound 11 (180 mg, $1.0 \mathrm{mmol})$ and isopropyl bromide $(183 \mathrm{mg}, 1.5 \mathrm{mmol})$ in anhydrous $\mathrm{CH}_{2} \mathrm{Cl}_{2}(2 \mathrm{~mL})$, dry mercury oxide/tetrafluoroboric acid $(190 \mathrm{mg}, 0.5 \mathrm{mmol})$ was added. The mixture was stirred at room temperature for $2 \mathrm{~h}$ and then treated successively with $\mathrm{NaHCO}_{3}$ and $3 \mathrm{M}$ potassium hydroxide until basic. The precipitated mercury oxide was filtered off and the filtrate was extracted with $\mathrm{CH}_{2} \mathrm{Cl}_{2}$. The organic layer was washed with brine, dried over anhydrous $\mathrm{Na}_{2} \mathrm{SO}_{4}$, and concentrated under vacuum. The residue was purified by column chromatography on silica gel (eluent: hexane/EtOAc $=25 / 1$ ) to give $14 \mathrm{c}(42 \mathrm{mg}, 19 \%)$ as a pale yellow liquid. ${ }^{1} \mathrm{H}-\mathrm{NMR}: \delta 8.19(\mathrm{~d}, J=2.0 \mathrm{~Hz}, 1 \mathrm{H}), 8.12(\mathrm{dd}, J=8.3$, $2.2 \mathrm{~Hz}, 1 \mathrm{H}), 7.35(\mathrm{~d}, J=8.3 \mathrm{~Hz}, 1 \mathrm{H}), 5.03(\mathrm{t}, J=6.3 \mathrm{~Hz}, 1 \mathrm{H}), 3.93-3.84(\mathrm{~m}, 1 \mathrm{H}), 3.15-3.09(\mathrm{~m}, 1 \mathrm{H})$, 2.94-2.82 (m, 1H), 2.54-2.48 (m, 1H), 2.12-2.05 (m, 1H), $1.29(\mathrm{~d}, J=6.1 \mathrm{~Hz}, 3 \mathrm{H}), 1.26(\mathrm{~d}, J=6.1 \mathrm{~Hz}, 3 \mathrm{H})$. ESI-MS: $m / z[\mathrm{M}+\mathrm{H}]^{+} 222$.

1-Butoxy-6-nitro-2,3-dihydro-1H-indene (14d). The title compound was prepared as a pale yellow liquid (69 mg, 29\%) from 11 and 1-bromobutane in a manner similar to that described for 14c. ${ }^{1} \mathrm{H}-\mathrm{NMR}$ : $\delta 8.22(\mathrm{~s}, 1 \mathrm{H}), 8.13(\mathrm{~d}, J=8.2 \mathrm{~Hz}, 1 \mathrm{H}), 7.36(\mathrm{~d}, J=8.2 \mathrm{~Hz}, 1 \mathrm{H}), 4.93(\mathrm{t}, J=5.5 \mathrm{~Hz}, 1 \mathrm{H}), 3.69-3.50(\mathrm{~m}, 2 \mathrm{H})$, 3.20-3.07 (m, 1H), 2.97-2.83 (m, 1H), 2.55-2.42 (m, 1H), 2.22-2.02 (m, 1H), 1.70-1.56 (m, 2H), $1.41(\mathrm{~m}$, 2H), $0.94(\mathrm{t}, J=6.4 \mathrm{~Hz}, 3 \mathrm{H}) ; \mathrm{ESI}-\mathrm{MS}: m / z[\mathrm{M}+\mathrm{H}]^{+} 236$.

5-Nitro-2,3-dihydro-1H-inden-2-ol (16). To a stirred solution of compound 12 (805 $\mathrm{mg}, 5.0 \mathrm{mmol}) \mathrm{in}$ anhydrous THF, diborane $(10 \mathrm{mmol})$ in diethyl sulfide $(5 \mathrm{~mL})$ was added dropwise at $0{ }^{\circ} \mathrm{C}$. The mixture was stirred at room temperature for $2 \mathrm{~h}$. A small amount of water was added until no bubbles were generated, then $30 \%$ hydrogen peroxide $(2.8 \mathrm{~mL})$ was added followed by the addition of $1 \mathrm{~N} \mathrm{NaOH}$ $(0.6 \mathrm{~mL})$. The mixture was stirred at room temperature for another $1 \mathrm{~h}$. After adding water $(50 \mathrm{~mL})$, the 
mixture was partitioned between water and EtOAc. The organic layer was washed with a saturated aqueous solution of brine, dried over anhydrous $\mathrm{Na}_{2} \mathrm{SO}_{4}$, and concentrated under vacuum. The residue was purified by column chromatography on silica gel (eluent: hexane/EtOAc = 3/1) to give 16 (295 mg, $33 \%$ ) as a white solid. m.p. 90 92 ${ }^{\circ} \mathrm{C} ;{ }^{1} \mathrm{H}-\mathrm{NMR}: \delta 8.10(\mathrm{~s}, 1 \mathrm{H}), 8.07(\mathrm{~d}, J=8.2 \mathrm{~Hz}, 1 \mathrm{H}), 7.37(\mathrm{~d}, J=8.2 \mathrm{~Hz}$, $1 \mathrm{H}), 4.85-4.77(\mathrm{~m}, 1 \mathrm{H}), 3.34-3.24(\mathrm{~m}, 2 \mathrm{H}), 3.01(\mathrm{~m}, 2 \mathrm{H})$; ESI-MS: $m / z[\mathrm{M}+\mathrm{H}]^{+} 180$.

2-Methoxy-5-nitro-2,3-dihydro-1H-indene (17a). The title compound was prepared from 16 and iodomethane in a manner similar to that described for $14 a$ as a pale yellow liquid (41\%). ${ }^{1} \mathrm{H}-\mathrm{NMR}$ : $\delta 8.08(\mathrm{~s}, 1 \mathrm{H}), 8.04(\mathrm{~d}, J=8.0 \mathrm{~Hz}, 1 \mathrm{H}), 7.35(\mathrm{~d}, J=8.2 \mathrm{~Hz}, 1 \mathrm{H}), 4.33-4.29(\mathrm{~m}, 1 \mathrm{H}), 3.38(\mathrm{~s}, 3 \mathrm{H}), 3.24-3.19$ $(\mathrm{m}, 2 \mathrm{H}), 3.11-3.06(\mathrm{~m}, 2 \mathrm{H})$;ESI-MS: $m / z[\mathrm{M}+\mathrm{H}]^{+} 194$.

2-Ethoxy-5-nitro-2,3-dihydro-1H-indene $\mathbf{( 1 7 b )}$. The title compound was prepared from 16 and iodoethane in a manner similar to that described for 14a as a pale yellow liquid $(26 \%)$. ${ }^{1} \mathrm{H}-\mathrm{NMR}: \delta 7.97(\mathrm{~d}$, $J=11.5 \mathrm{~Hz}, 2 \mathrm{H}), 7.27(\mathrm{~s}, 1 \mathrm{H}), 4.37-4.30(\mathrm{~m}, 1 \mathrm{H}), 3.48(\mathrm{q}, J=7.0 \mathrm{~Hz}, 2 \mathrm{H}), 3.15(\mathrm{dd}, J=17.0,6.3 \mathrm{~Hz}, 2 \mathrm{H})$, $2.99(\mathrm{dt}, J=9.1,4.3 \mathrm{~Hz}, 2 \mathrm{H}), 1.14(\mathrm{t}, J=7.0 \mathrm{~Hz}, 3 \mathrm{H})$;ESI-MS: $m / z[\mathrm{M}+\mathrm{H}]^{+} 208$.

2-Methylene-2,3-dihydro-1H-inden-1-one (19a). To a solution of 9 (1.32 g, $10.0 \mathrm{mmol})$ and paraformaldehyde $(1.50 \mathrm{~g}, 5.0 \mathrm{eq})$ in glacial acetic acid $(20 \mathrm{~mL})$, morpholine $(0.5 \mathrm{~mL})$ was added. The mixture was refluxed under nitrogen for $2 \mathrm{~h}$. The glacial acetic acid was removed by distillation. After adding water $(50 \mathrm{~mL})$, the mixture was partitioned between water and EtOAc. The organic layer was washed with brine, dried over anhydrous $\mathrm{Na}_{2} \mathrm{SO}_{4}$, and concentrated under vacuum. The residue was purified by column chromatography on silica gel (eluent: hexane/EtOAc $=7 / 1)$ to give $19 a(0.45 \mathrm{~g}$, 31\%) to give a yellow liquid. ${ }^{1} \mathrm{H}-\mathrm{NMR}: \delta 7.89(\mathrm{~d}, J=7.6 \mathrm{~Hz}, 1 \mathrm{H}), 7.62(\mathrm{t}, J=7.4 \mathrm{~Hz}, 1 \mathrm{H}), 7.51(\mathrm{~d}$, $J=7.6 \mathrm{~Hz}, 1 \mathrm{H}), 7.42(\mathrm{t}, J=7.4 \mathrm{~Hz}, 1 \mathrm{H}), 6.39(\mathrm{~s}, 1 \mathrm{H}), 5.65(\mathrm{~s}, 1 \mathrm{H}), 3.78(\mathrm{~s}, 2 \mathrm{H}) ; \mathrm{ESI}-\mathrm{MS}: m / z[\mathrm{M}+\mathrm{H}]^{+} 145$.

2-(Propan-2-ylidene)-2,3-dihydro-1H-inden-1-one (19b). To a solution of $\mathbf{9}$ (1.32 g, $10.0 \mathrm{mmol})$ in anhydrous acetone $(20 \mathrm{~mL}), \mathrm{NaOH}(132 \mathrm{mg}, 3.3 \mathrm{mmol})$ was added at room temperature. The mixture was stirred at room temperature for $4 \mathrm{~h}$ and then neutralized with $1 \mathrm{~N} \mathrm{HCl}$. Acetone was removed by distillation. After adding water $(50 \mathrm{~mL})$, the mixture was partitioned between water and EtOAc. The organic layer was washed with brine, dried over anhydrous $\mathrm{Na}_{2} \mathrm{SO}_{4}$, and concentrated under vacuum. The residue was purified by column chromatography on silica gel (eluent: hexane/EtOAc $=7 / 1)$ to give $19 b(0.77 \mathrm{~g}$, $45 \%)$ as a yellow solid. m.p. $98 \sim 100{ }^{\circ} \mathrm{C} ;{ }^{1} \mathrm{H}-\mathrm{NMR}: \delta 7.81(\mathrm{~d}, J=7.6 \mathrm{~Hz}, 1 \mathrm{H}), 7.55(\mathrm{~d}, J=7.1 \mathrm{~Hz}, 1 \mathrm{H})$, $7.47(\mathrm{~s}, 1 \mathrm{H}), 7.37$ (s, 1H), 3.65 (s, 2H), 2.45 (s, 3H), $2.01(\mathrm{~s}, 3 \mathrm{H})$; ESI-MS: $m / z[\mathrm{M}+\mathrm{H}]^{+} 173$.

2-Methyl-2,3-dihydro-1H-inden-1-one (20a). To a solution of 19a (1.44 g, $10 \mathrm{mmol})$ in EtOAc (20 mL), $10 \% \mathrm{Pd} / \mathrm{C}(20 \%$ weight of compound 19a) was added. The mixture was stirred overnight under a hydrogen atmosphere at room temperature. Insoluble materials were removed by filtration and washed with EtOAc. The filtrate was evaporated to dryness under reduced pressure to give $20 \mathrm{a}(1.43 \mathrm{~g}$, $98 \%)$ as a colorless transparent liquid. ${ }^{1} \mathrm{H}-\mathrm{NMR}: \delta 7.76(\mathrm{~d}, J=7.7 \mathrm{~Hz}, 1 \mathrm{H}), 7.59(\mathrm{~d}, J=7.6,1 \mathrm{H}), 7.45(\mathrm{~d}$, $J=7.7 \mathrm{~Hz}, 1 \mathrm{H}), 7.37(\mathrm{t}, J=7.4 \mathrm{~Hz}, 1 \mathrm{H}), 3.45-3.36(\mathrm{~m}, 1 \mathrm{H}), 2.79-2.68(\mathrm{~m}, 2 \mathrm{H}), 1.35-1.30(\mathrm{~m}, 3 \mathrm{H})$; ESI-MS: $m / z[\mathrm{M}+\mathrm{H}]^{+} 147$.

2-Isopropyl-2,3-dihydro-1H-inden-1-one (20b). The title compound was prepared from $\mathbf{1 9 b}$ in a manner similar to that described for $\mathbf{2 0 a}$ as a colorless transparent liquid $(97 \%)$. ${ }^{1} \mathrm{H}-\mathrm{NMR}: \delta 7.75(\mathrm{~d}, J=7.7 \mathrm{~Hz}$, $1 \mathrm{H}), 7.59(\mathrm{td}, J=7.6,1.1 \mathrm{~Hz}, 1 \mathrm{H}), 7.49(\mathrm{~d}, J=7.7 \mathrm{~Hz}, 1 \mathrm{H}), 7.39-7.34(\mathrm{~m}, 1 \mathrm{H}), 3.16(\mathrm{dd}, J=17.4,8.1 \mathrm{~Hz}$, $1 \mathrm{H}), 2.95(\mathrm{dd}, J=17.4,4.0 \mathrm{~Hz}, 1 \mathrm{H}), 2.82-2.79(\mathrm{~m}, 1 \mathrm{H}), 2.45-2.42(\mathrm{~m}, 1 \mathrm{H}), 1.07(\mathrm{~d}, J=6.9 \mathrm{~Hz}, 3 \mathrm{H}), 0.81$ $(\mathrm{d}, J=6.8 \mathrm{~Hz}, 3 \mathrm{H})$; ESI-MS: $m / z[\mathrm{M}+\mathrm{H}]^{+} 175$.

2-Methyl-6-nitro-2,3-dihydro-1H-inden-1-one (21a). The title compound was prepared from 20a in a manner similar to that described for 10 as a yellow solid $(67 \%)$. m.p. $64 \sim 66{ }^{\circ} \mathrm{C} ;{ }^{1} \mathrm{H}-\mathrm{NMR}: \delta 8.58(\mathrm{~d}$, $J=2.1 \mathrm{~Hz}, 1 \mathrm{H}), 8.46(\mathrm{dd}, J=8.4,2.2 \mathrm{~Hz}, 1 \mathrm{H}), 7.64(\mathrm{~d}, J=8.4 \mathrm{~Hz}, 1 \mathrm{H}), 3.55-3.50(\mathrm{~m}, 1 \mathrm{H}), 2.91-2.79(\mathrm{~m}$, 2H), $1.37(\mathrm{~d}, J=7.3 \mathrm{~Hz}, 3 \mathrm{H})$; ESI-MS: $m / z[\mathrm{M}+\mathrm{H}]^{+} 192$.

2-Isopropyl-6-nitro-2,3-dihydro-1H-inden-1-one (21b). The title compound was prepared from 20b in a manner similar to that described for 10 as a yellow solid $(73 \%)$. m.p. $72 \sim 76{ }^{\circ} \mathrm{C} ;{ }^{1} \mathrm{H}-\mathrm{NMR}: \delta 8.55$ (d, 
$J=2.0 \mathrm{~Hz}, 1 \mathrm{H}), 8.44(\mathrm{dd}, J=8.4,2.2 \mathrm{~Hz}, 1 \mathrm{H}), 7.65(\mathrm{~d}, J=8.3 \mathrm{~Hz}, 1 \mathrm{H}), 3.28(\mathrm{dd}, J=18.3,8.2 \mathrm{~Hz}, 1 \mathrm{H})$, $3.04(\mathrm{dd}, J=18.3,4.1 \mathrm{~Hz}, 1 \mathrm{H}), 2.82-2.79(\mathrm{~m}, 1 \mathrm{H}), 2.51-2.40(\mathrm{~m}, 1 \mathrm{H}), 1.07(\mathrm{~d}, J=6.9 \mathrm{~Hz}, 3 \mathrm{H}), 0.83(\mathrm{~d}$, $J=6.8 \mathrm{~Hz}, 3 \mathrm{H})$; ESI-MS: $m / z[\mathrm{M}+\mathrm{H}]^{+} 192$.

2-Methyl-6-nitro-2,3-dihydro-1H-inden-1-ol (22a). The title compound was prepared from 21a in a manner similar to that described for $\mathbf{1 1}$ as a white solid (86\%). m.p. $81 \sim 84{ }^{\circ} \mathrm{C} ;{ }^{1} \mathrm{H}-\mathrm{NMR}: \delta 8.58(\mathrm{~d}, J=5.0 \mathrm{~Hz}$, $1 \mathrm{H}), 8.06(\mathrm{~s}, 1 \mathrm{H}), 7.45(\mathrm{~d}, J=8.0 \mathrm{~Hz}, 1 \mathrm{H}), 5.72(\mathrm{~d}, J=6.0 \mathrm{~Hz}, 1 \mathrm{H}), 4.62-4.59(\mathrm{~s}, 1 \mathrm{H}), 3.10-3.05(\mathrm{~m}, 1 \mathrm{H})$, 2.58-2.53 (m, 1H), 2.24-2.14 (m, 1H), $1.20(\mathrm{~d}, J=6.7 \mathrm{~Hz}, 3 \mathrm{H})$;ESI-MS: $m / z[\mathrm{M}+\mathrm{H}]^{+} 194$.

2-Isopropyl-6-nitro-2,3-dihydro-1H-inden-1-ol (22b). The title compound was prepared from $\mathbf{2 1 \mathbf { b }}$ in a manner similar to that described for $\mathbf{1 1}$ as a white solid (89\%). m.p. 90 93 ${ }^{\circ} \mathrm{C} ;{ }^{1} \mathrm{H}-\mathrm{NMR}$ : $\delta 8.15-8.04$ $(\mathrm{m}, 1 \mathrm{H}), 7.70(\mathrm{~m}, 1 \mathrm{H}), 7.41(\mathrm{~m}, 1 \mathrm{H}), 3.22(\mathrm{~d}, J=3.3 \mathrm{~Hz}, 1 \mathrm{H}), 3.54(\mathrm{dd}, J=17.9,7.3 \mathrm{~Hz}, 1 \mathrm{H}), 3.15(\mathrm{dd}$, $J=17.9,9.8 \mathrm{~Hz}, 1 \mathrm{H}), 2.05-1.92(\mathrm{~m}, 1 \mathrm{H}), 1.55(\mathrm{~m}, 1 \mathrm{H}), 1.14(\mathrm{t}, J=5.5 \mathrm{~Hz}, 3 \mathrm{H}), 1.09(\mathrm{~d}, J=6.5 \mathrm{~Hz}, 3 \mathrm{H}))$; ESI-MS: $m / z[\mathrm{M}+\mathrm{H}]^{+} 222$.

2-Methyl-5-nitro-1H-indene (23a). The title compound was prepared from 22a in a manner similar to that described for 12 as a white solid (81\%). m.p.: $68 \sim 72{ }^{\circ} \mathrm{C} ;{ }^{1} \mathrm{H}-\mathrm{NMR}: \delta 7.76(\mathrm{~d}, J=7.6 \mathrm{~Hz}, 1 \mathrm{H}), 7.59(\mathrm{t}$, $J=7.4 \mathrm{~Hz}, 1 \mathrm{H}), 7.46(\mathrm{~d}, J=7.7 \mathrm{~Hz}, 1 \mathrm{H}), 5.02(\mathrm{~d}, J=5.9 \mathrm{~Hz}, 1 \mathrm{H}), 3.41(\mathrm{~s}, 8.7 \mathrm{~Hz}, 2 \mathrm{H}), 1.32(\mathrm{~d}, J=7.2 \mathrm{~Hz}$, 3H); ESI-MS: $m / z[\mathrm{M}+\mathrm{H}]^{+} 176$.

2-Isopropyl-5-nitro-1H-indene (23b). The title compound was prepared from $\mathbf{2 2 b}$ in a manner similar to that described for 12 as a white solid (82\%). m.p. $78 \sim 81{ }^{\circ} \mathrm{C} ;{ }^{1} \mathrm{H}-\mathrm{NMR}: \delta 8.07(\mathrm{~d}, J=1.8 \mathrm{~Hz}, 1 \mathrm{H}), 8.00$ $(\mathrm{dd}, J=8.1,1.8 \mathrm{~Hz}, 1 \mathrm{H}), 7.46(\mathrm{~d}, J=8.1 \mathrm{~Hz}, 1 \mathrm{H}), 6.56(\mathrm{~s}, 1 \mathrm{H}), 3.44(\mathrm{~s}, 2 \mathrm{H}), 2.90-2.73(\mathrm{~m}, 1 \mathrm{H}), 1.25(\mathrm{~s}, 3 \mathrm{H})$, 1.24 (s, 3H); ESI-MS: $m / z[\mathrm{M}+\mathrm{H}]^{+} 204$.

1-Methoxy-2-methyl-6-nitro-2,3-dihydro-1H-indene (27a). To a solution of 22a (106 mg, $0.55 \mathrm{mmol}$ ) and trimethyl orthoformate $(1 \mathrm{~mL})$ in anhydrous $\mathrm{CH}_{2} \mathrm{Cl}_{2}(2 \mathrm{~mL})$, bismuth trichloride (173 $\left.\mathrm{mg}, 0.55 \mathrm{mmol}\right)$ was added at room temperature. The mixture was stirred at room temperature for $7 \mathrm{~h}$ and then treated with aqueous $1 \mathrm{~N} \mathrm{NaHCO}_{3}$ until basic. After adding water $(50 \mathrm{~mL})$, the mixture was partitioned between water and EtOAc. The organic layer was washed with a saturated aqueous solution of brine, dried over anhydrous $\mathrm{Na}_{2} \mathrm{SO}_{4}$, and concentrated under vacuum. The residue was purified by column chromatography on silica gel (eluent: hexane $/ \mathrm{EtOAc}=30 / 1)$ to give $27 \mathrm{a}(27 \mathrm{mg}, 24 \%)$ as a yellow oil. ${ }^{1} \mathrm{H}-\mathrm{NMR}: \delta 8.22(\mathrm{~s}, 1 \mathrm{H}), 8.15(\mathrm{dd}, J=8.3,2.1 \mathrm{~Hz}, 1 \mathrm{H}), 7.35(\mathrm{~d}, J=8.3 \mathrm{~Hz}, 1 \mathrm{H}), 4.42(\mathrm{~d}, J=4.4 \mathrm{~Hz}, 1 \mathrm{H})$, $3.52(\mathrm{~s}, 3 \mathrm{H}), 3.31-3.26(\mathrm{~m}, 1 \mathrm{H}), 2.64-2.56(\mathrm{~m}, 1 \mathrm{H}), 2.56-2.50(\mathrm{~m}, 1 \mathrm{H}), 1.19(\mathrm{~d}, J=7.0 \mathrm{~Hz}, 3 \mathrm{H})$; ESI-MS: $m / z[\mathrm{M}+\mathrm{H}]^{+} 208$.

1-Ethoxy-2-methyl-6-nitro-2,3-dihydro-1H-indene (27b). The title compound was prepared from $\mathbf{2 2 b}$ and triethyl orthoformate in a manner similar to that described for $27 \mathbf{a}$ as yellow oil (33\%). ${ }^{1} \mathrm{H}-\mathrm{NMR}$ : $\delta 8.26$ $(\mathrm{s}, 1 \mathrm{H}), 8.16(\mathrm{~d}, J=8.3 \mathrm{~Hz}, 1 \mathrm{H}), 7.38(\mathrm{~d}, J=8.1 \mathrm{~Hz}, 1 \mathrm{H}), 4.92(\mathrm{~d}, J=6.4 \mathrm{~Hz}, 1 \mathrm{H}), 3.65(\mathrm{~d}, J=7.0 \mathrm{~Hz}$, $2 \mathrm{H}), 2.80-2.73(\mathrm{~m}, 2 \mathrm{H}), 2.65(\mathrm{q}, J=6.5,1 \mathrm{H}), 1.33(\mathrm{~d}, J=6.6 \mathrm{~Hz}, 3 \mathrm{H}), 1.31-1.27(\mathrm{~m}, 3 \mathrm{H})$; ESI-MS: $m / z$ $[\mathrm{M}+\mathrm{H}]^{+} 222$.

2-Isopropyl-1-methoxy-6-nitro-2,3-dihydro-1H-indene (28a). The title compound was prepared from 22a in a manner similar to that described for 27 a as yellow oil $(27 \%) .{ }^{1} \mathrm{H}-\mathrm{NMR}: \delta 8.20(\mathrm{~d}, J=2.0 \mathrm{~Hz}, 1 \mathrm{H})$, $8.18(\mathrm{dd}, J=8.2,2.2 \mathrm{~Hz}, 1 \mathrm{H}), 7.41(\mathrm{~d}, J=8.2 \mathrm{~Hz}, 1 \mathrm{H}), 4.51(\mathrm{~d}, J=3.2 \mathrm{~Hz}, 1 \mathrm{H}), 3.34(\mathrm{~s}, 3 \mathrm{H}), 3.00-2.86(\mathrm{~m}$, 2H), 2.09-2.01 (m, 1H), 2.00-1.95 (m, 1H), $1.07(\mathrm{~d}, J=6.3 \mathrm{~Hz}, 3 \mathrm{H}), 1.00(\mathrm{~d}, J=6.6 \mathrm{~Hz}, 3 \mathrm{H})$; ESI-MS: $m / z$ $[\mathrm{M}+\mathrm{H}]^{+} 236$.

1-Ethoxy-2-isopropyl-6-nitro-2,3-dihydro-1H-indene (28b). The title compound was prepared from $\mathbf{2 2 b}$ and triethyl orthoformate in a manner similar to that described for $27 \mathrm{a}$ as yellow oil (19\%). ${ }^{1} \mathrm{H}-\mathrm{NMR}$ : $\delta 8.25(\mathrm{~d}, J=4.4 \mathrm{~Hz}, 1 \mathrm{H}), 8.14(\mathrm{dd}, J=8.3,2.2 \mathrm{~Hz}, 1 \mathrm{H}), 7.35(\mathrm{~d}, J=8.3 \mathrm{~Hz}, 1 \mathrm{H}), 4.62(\mathrm{~d}, J=5.3 \mathrm{~Hz}, 1 \mathrm{H})$, $3.20(\mathrm{q}, J=8.5 \mathrm{~Hz}, 2 \mathrm{H}), 2.83-2.75(\mathrm{~m}, 2 \mathrm{H}), 2.66-2.56(\mathrm{~m}, 1 \mathrm{H}), 2.19-2.06(\mathrm{~m}, 1 \mathrm{H}), 1.09(\mathrm{~d}, J=6.5 \mathrm{~Hz}, 5 \mathrm{H})$, 1.01-0.99 (m, 3H); ESI-MS: $m / z[\mathrm{M}+\mathrm{H}]^{+} 250$. 
Dimethyl Terephthalate (32). To a solution of terephthalic acid (31, 6.0 g, $36.0 \mathrm{mmol})$ in methanol (150 $\mathrm{mL})$, thionyl chloride $(7.7 \mathrm{~mL}, 108 \mathrm{mmol})$ was added dropwise at $0{ }^{\circ} \mathrm{C}$. The mixture was stirred at room temperature for $17 \mathrm{~h}$ and then saturated potassium carbonate solution was added until no bubbles were generated. The methanol was removed by distillation. After adding water ( $40 \mathrm{~mL})$, the mixture was partitioned between water and ether. The organic layer was washed with a saturated aqueous solution of $\mathrm{NaHCO}_{3}$ and brine, dried over anhydrous $\mathrm{Na}_{2} \mathrm{SO}_{4}$, and concentrated under vacuum to give 32 (6.84 g, 98\%) as a white solid. m.p. 141 143 ${ }^{\circ} \mathrm{C}$ (ether); ESI-MS: $m / z[\mathrm{M}+\mathrm{H}]^{+} 195$.

4-(Methoxycarbonyl)benzoic acid (33). To a solution of $32(2.0 \mathrm{~g}, 10.0 \mathrm{mmol})$ in methanol and ether (methanol:ether $=1: 1,20 \mathrm{~mL})$, a solution of $\mathrm{KOH}(0.58 \mathrm{~g}, 10.0 \mathrm{mmol})$ in methanol and water (methanol:water $=10: 1,10 \mathrm{~mL}$ ) was added dropwise at $0{ }^{\circ} \mathrm{C}$. The mixture was stirred at room temperature for $24 \mathrm{~h}$. After adding water $(50 \mathrm{~mL})$, the mixture was partitioned between water and ether. Then treating the aqueous layer successively with $1 \mathrm{~N} \mathrm{HCl}$ until $\mathrm{pH}=1$. The mixture was partitioned between water and EtOAc. The organic layer was washed with a saturated aqueous solution of brine, dried over anhydrous $\mathrm{Na}_{2} \mathrm{SO}_{4}$, and concentrated under vacuum to give 33 (1.0 g, $56 \%$ ) as a white solid. m.p. $188 \sim 192{ }^{\circ} \mathrm{C}$.

4-((2,3-Dihydro-1H-inden-5-yl)carbamoyl) benzoate (35a). To a solution of 12 (80.5 mg, $0.5 \mathrm{mmol})$ in EtOAc $(20 \mathrm{~mL}), 10 \% \mathrm{Pd} / \mathrm{C}(20 \%$ net weight of compound 19a) was added. The mixture was stirred overnight under a hydrogen atmosphere at room temperature. Insoluble materials were removed by filtration and washed with EtOAc. The filtrate was evaporated to dryness under reduced pressure to give 13 as brown oil (65 mg, 98\%). To a solution of 33 (150 mg, $0.8 \mathrm{mmol})$ in thionyl chloride $(4 \mathrm{~mL})$, a drop of pyridine was added and refluxed for $24 \mathrm{~h}$. The thionyl chloride was removed by distillation and get 34 as pale yellow solid. 34 was used directly in the next reaction. To a solution of $13(65 \mathrm{mg}, 0.5 \mathrm{mmol})$ in anhydrous pyridine $(2 \mathrm{~mL}), 34$ was added in $\mathrm{CH}_{2} \mathrm{Cl}_{2}(2 \mathrm{~mL})$ dropwise at $0{ }^{\circ} \mathrm{C}$. The mixture was stirred at room temperature for $7 \mathrm{~h}$ and then the methanol was removed by distillation. The organic layer was treated successively with $1 \mathrm{~N} \mathrm{HCl}$ until acidic. The mixture was partitioned between water and EtOAc. The organic layer was washed with a saturated aqueous solution of brine, dried over anhydrous $\mathrm{Na}_{2} \mathrm{SO}_{4}$, and concentrated under vacuum. The residue was purified by column chromatography on silica gel (eluent: hexane/EtOAc $=3 / 1)$ to give 35a $(118 \mathrm{mg}$, $80 \%$ ) as a pale yellow solid. m.p. $138 \sim 142{ }^{\circ} \mathrm{C} ;{ }^{1} \mathrm{H}-\mathrm{NMR}: \delta 8.15(\mathrm{~d}, J=6.9 \mathrm{~Hz}, 2 \mathrm{H}), 7.93(\mathrm{~d}, J=8.1 \mathrm{~Hz}$, 2H), $7.60(\mathrm{~s}, 1 \mathrm{H}), 7.30(\mathrm{~d}, J=8.1 \mathrm{~Hz}, 1 \mathrm{H}), 7.22(\mathrm{~d}, J=7.9 \mathrm{~Hz}, 1 \mathrm{H}), 3.96(\mathrm{~s}, 3 \mathrm{H}), 2.95-2.89(\mathrm{~m}, 4 \mathrm{H}), 2.13-2.07$ (m, 2H);ESI-MS: $m / z[\mathrm{M}+\mathrm{H}]^{+} 296$.

Methyl 4-((3-methoxy-2,3-dihydro-1H-inden-5-yl)carbamoyl) benzoate (35b). The title compound was prepared from 14a in a manner similar to that described for 35a as a pale yellow solid (87\%). m.p. 148 151 ${ }^{\circ} \mathrm{C} ;{ }^{1} \mathrm{H}-\mathrm{NMR}: \delta 8.15(\mathrm{~d}, J=8.3 \mathrm{~Hz}, 2 \mathrm{H}), 7.92(\mathrm{~d}, J=8.3 \mathrm{~Hz}, 2 \mathrm{H}), 7.86(\mathrm{~s}, 1 \mathrm{H}), 7.72(\mathrm{~s}, 1 \mathrm{H}), 7.50(\mathrm{~d}$, $J=7.3 \mathrm{~Hz}, 1 \mathrm{H}), 7.27(\mathrm{~d}, J=8.0 \mathrm{~Hz}, 1 \mathrm{H}), 4.83(\mathrm{dd}, J=6.5,4.2 \mathrm{~Hz}, 1 \mathrm{H}), 3.96(\mathrm{~s}, 3 \mathrm{H}), 3.43(\mathrm{~s}, 3 \mathrm{H}), 3.11-3.01$ $(\mathrm{m}, 1 \mathrm{H}), 2.85-2.77(\mathrm{~m}, 1 \mathrm{H}), 2.42-2.32(\mathrm{~m}, 1 \mathrm{H}), 2.11-2.08(\mathrm{~m}, 1 \mathrm{H})$; ESI-MS: $m / z[\mathrm{M}+\mathrm{H}]^{+} 326$.

Methyl 4-((3-ethoxy-2,3-dihydro-1H-inden-5-yl)carbamoyl) benzoate (35c). The title compound was prepared from $\mathbf{1 4 b}$ in a manner similar to that described for $35 \mathrm{a}$ as a pale yellow solid (76\%). m.p. 153 156 ${ }^{\circ} \mathrm{C} ;{ }^{1} \mathrm{H}-\mathrm{NMR}: \delta 8.16(\mathrm{~d}, J=8.2 \mathrm{~Hz}, 2 \mathrm{H}), 7.93(\mathrm{~d}, J=8.1 \mathrm{~Hz}, 2 \mathrm{H}), 7.82(\mathrm{~s}, 1 \mathrm{H}), 7.71(\mathrm{~s}, 1 \mathrm{H}), 7.50(\mathrm{~d}$, $J=7.7 \mathrm{~Hz}, 1 \mathrm{H}), 7.24(\mathrm{~d}, J=8.0 \mathrm{~Hz}, 1 \mathrm{H}), 4.96-4.89(\mathrm{~m}, 1 \mathrm{H}), 3.97(\mathrm{~s}, 3 \mathrm{H}), 3.64(\mathrm{q}, J=6.8,2 \mathrm{H}), 3.09-3.03(\mathrm{~m}$, $1 \mathrm{H}), 2.83-2.77(\mathrm{~m}, 1 \mathrm{H}), 2.44-2.36(\mathrm{~m}, J=6.7 \mathrm{~Hz}, 1 \mathrm{H}), 2.12-2.06(\mathrm{~m}, 1 \mathrm{H}), 1.25(\mathrm{t}, J=7.0 \mathrm{~Hz}, 3 \mathrm{H})$; ESI-MS: $m / z[\mathrm{M}+\mathrm{H}]^{+} 340$.

Methyl 4-((3-isopropoxy-2,3-dihydro-1H-inden-5-yl)carbamoyl) benzoate (35d). The title compound was prepared from 14c in a manner similar to that described for 35a as a pale yellow solid (79\%). m.p. 150 153 ${ }^{\circ} \mathrm{C} ;{ }^{1} \mathrm{H}-\mathrm{NMR}: \delta 8.16(\mathrm{~d}, J=7.7 \mathrm{~Hz}, 2 \mathrm{H}), 7.93(\mathrm{~d}, J=7.6 \mathrm{~Hz}, 2 \mathrm{H}), 7.80(\mathrm{~s}, 1 \mathrm{H}), 7.50(\mathrm{~d}, J=7.2 \mathrm{~Hz}$, $1 \mathrm{H}), 7.23(\mathrm{~d}, J=8.3 \mathrm{~Hz}, 1 \mathrm{H}), 5.01(\mathrm{t}, J=5.9 \mathrm{~Hz}, 1 \mathrm{H}), 3.96(\mathrm{~s}, 3 \mathrm{H}), 3.92-3.83(\mathrm{~m}, 1 \mathrm{H}), 3.03(\mathrm{~s}, 1 \mathrm{H}), 2.78(\mathrm{dt}$, $J=15.7,7.8 \mathrm{~Hz}, 1 \mathrm{H}), 2.44(\mathrm{~d}, J=6.2 \mathrm{~Hz}, 1 \mathrm{H}), 2.03(\mathrm{dt}, J=13.1,8.5 \mathrm{~Hz}, 1 \mathrm{H}), 1.25(\mathrm{~s}, 6 \mathrm{H})$; ESI-MS: $m / z$ $[\mathrm{M}+\mathrm{H}]^{+} 354$. 
Methyl 4-((3-isopropoxy-2,3-dihydro-1H-inden-5-yl)carbamoyl) benzoate (35e). The title compound was prepared from 14d in a manner similar to that described for 35a as a pale yellow solid (73\%). m.p. 159 160 ${ }^{\circ} \mathrm{C} ;{ }^{1} \mathrm{H}-\mathrm{NMR}: \delta 8.16(\mathrm{~d}, J=8.3 \mathrm{~Hz}, 2 \mathrm{H}), 7.93(\mathrm{~d}, J=8.2 \mathrm{~Hz}, 2 \mathrm{H}), 7.81(\mathrm{~s}, 1 \mathrm{H}), 7.66(\mathrm{~s}, 1 \mathrm{H}), 7.52$ $(\mathrm{d}, J=7.8 \mathrm{~Hz}, 1 \mathrm{H}), 7.24(\mathrm{~s}, 1 \mathrm{H}), 4.93-4.85(\mathrm{~m}, 1 \mathrm{H}), 3.96(\mathrm{~s}, 3 \mathrm{H}), 3.57(\mathrm{dd}, J=15.4,6.7 \mathrm{~Hz}, 2 \mathrm{H}), 3.04(\mathrm{ddd}$, $J=16.8,11.4,7.0 \mathrm{~Hz}, 1 \mathrm{H}), 2.79(\mathrm{~s}, 1 \mathrm{H}), 2.40(\mathrm{dq}, J=8.2,6.2 \mathrm{~Hz}, 1 \mathrm{H}), 2.15-1.99(\mathrm{~m}, 1 \mathrm{H}), 1.67-1.58(\mathrm{~m}$, 2H), $1.41(\mathrm{dd}, J=13.2,7.5 \mathrm{~Hz}, 2 \mathrm{H}), 0.96-0.89(\mathrm{~m}, 3 \mathrm{H})$; ESI-MS: $m / z[\mathrm{M}+\mathrm{H}]^{+} 368$.

Methyl 4-((3-isopropoxy-2,3-dihydro-1H-inden-5-yl)carbamoyl) benzoate (35f). The title compound was prepared from 17a in a manner similar to that described for $35 \mathrm{a}$ as a yellow solid (66\%). m.p. 134 135 ${ }^{\circ} \mathrm{C} ;{ }^{1} \mathrm{H}-\mathrm{NMR}: \delta 8.16(\mathrm{~d}, J=8.4 \mathrm{~Hz}, 2 \mathrm{H}), 7.92(\mathrm{~d}, J=8.2 \mathrm{~Hz}, 2 \mathrm{H}), 7.75(\mathrm{~s}, 1 \mathrm{H}), 7.63(\mathrm{~s}, 1 \mathrm{H}), 7.31$ $(\mathrm{d}, J=5.7 \mathrm{~Hz}, 1 \mathrm{H}), 4.28(\mathrm{t}, J=5.3 \mathrm{~Hz}, 1 \mathrm{H}), 3.97(\mathrm{~s}, 3 \mathrm{H}), 3.39(\mathrm{~s}, 3 \mathrm{H}), 3.21-3.13(\mathrm{~m}, 2 \mathrm{H}), 3.03-2.95(\mathrm{~m}, 2 \mathrm{H})$; ESI-MS: $m / z[\mathrm{M}+\mathrm{H}]^{+} 326$.

Methyl 4-((3-isopropoxy-2,3-dihydro-1H-inden-5-yl)carbamoyl) benzoate (35g). The title compound was prepared from $\mathbf{1 7 b}$ in a manner similar to that described for $35 \mathbf{a}$ as a yellow solid (71\%). m.p. 137 139 ${ }^{\circ} \mathrm{C} ;{ }^{1} \mathrm{H}-\mathrm{NMR}: \delta 8.16(\mathrm{~d}, J=8.3 \mathrm{~Hz}, 2 \mathrm{H}), 7.92(\mathrm{~d}, J=8.3 \mathrm{~Hz}, 2 \mathrm{H}), 7.75(\mathrm{~s}, 1 \mathrm{H}), 7.62(\mathrm{~s}, 1 \mathrm{H}), 7.30$ $(\mathrm{d}, J=9.3 \mathrm{~Hz}, 1 \mathrm{H}), 7.20(\mathrm{~d}, J=7.8 \mathrm{~Hz}, 1 \mathrm{H}), 4.37(\mathrm{t}, J=5.0 \mathrm{~Hz}, 1 \mathrm{H}), 3.56(\mathrm{~d}, J=7.0 \mathrm{~Hz}, 2 \mathrm{H}), 3.21-3.14(\mathrm{~m}$, 2H), 3.04-2.93 (m, 2H), $1.23(\mathrm{t}, J=7.0 \mathrm{~Hz}, 3 \mathrm{H})$; ESI-MS: $m / z[\mathrm{M}+\mathrm{H}]^{+} 340$.

Methyl 4-((3-isopropoxy-2,3-dihydro-1H-inden-5-yl)carbamoyl) benzoate (35h). The title compound was prepared from $\mathbf{2 3 b}$ in a manner similar to that described for $35 \mathbf{a}$ as a pale yellow solid (87\%). m.p. 144 149 ${ }^{\circ} \mathrm{C} ;{ }^{1} \mathrm{H}-\mathrm{NMR}: \delta 8.19(\mathrm{~d}, J=8.3 \mathrm{~Hz}, 2 \mathrm{H}), 7.98(\mathrm{~s}, 1 \mathrm{H}), 8.00-7.93(\mathrm{~m}, 2 \mathrm{H}), 7.84(\mathrm{~s}, 1 \mathrm{H}), 7.54(\mathrm{~d}$, $J=8.2 \mathrm{~Hz}, 1 \mathrm{H}), 3.98(\mathrm{~d}, J=4.4 \mathrm{~Hz}, 3 \mathrm{H}), 3.21-3.11(\mathrm{~m}, 3 \mathrm{H}), 2.79-2.70(\mathrm{~m}, 3 \mathrm{H}), 1.25(\mathrm{~d}, J=20.0 \mathrm{~Hz}, 6 \mathrm{H})$; ESI-MS: $m / z[\mathrm{M}+\mathrm{H}]^{+} 338$.

Methyl 4-((3-isopropoxy-2,3-dihydro-1H-inden-5-yl)carbamoyl) benzoate (35k). The title compound was prepared from 21a in a manner similar to that described for 35a as a pale yellow solid (77\%). m.p. 167 171 ${ }^{\circ} \mathrm{C} ;{ }^{1} \mathrm{H}-\mathrm{NMR}: \delta 8.17(\mathrm{~s}, 2 \mathrm{H}), 8.11(\mathrm{~d}, J=6.4 \mathrm{~Hz}, 1 \mathrm{H}), 7.96(\mathrm{~s}, 2 \mathrm{H}), 7.82(\mathrm{~s}, 1 \mathrm{H}), 7.50(\mathrm{~d}, J=8.2 \mathrm{~Hz}$, $1 \mathrm{H}), 3.97(\mathrm{~s}, 3 \mathrm{H}), 3.41(\mathrm{dd}, J=16.4,7.3 \mathrm{~Hz}, 1 \mathrm{H}), 2.80-2.75(\mathrm{~m}, 1 \mathrm{H}), 2.75(\mathrm{~s}, 1 \mathrm{H}), 1.33(\mathrm{~d}, J=7.3 \mathrm{~Hz}, 3 \mathrm{H})$; ESI-MS: $m / z[\mathrm{M}+\mathrm{H}]^{+} 324$.

Methyl 4-((3-isopropoxy-2,3-dihydro-1H-inden-5-yl)carbamoyl) benzoate (351). The title compound was prepared from $\mathbf{2 1 b}$ in a manner similar to that described for $35 \mathrm{a}$ as a pale yellow solid (89\%). m.p. 170 174 ${ }^{\circ} \mathrm{C} ;{ }^{1} \mathrm{H}-\mathrm{NMR}: \delta 8.21(\mathrm{~d}, J=8.2 \mathrm{~Hz}, 1 \mathrm{H}), 8.18(\mathrm{~d}, J=8.4 \mathrm{~Hz}, 2 \mathrm{H}), 8.00(\mathrm{~d}, J=8.2 \mathrm{~Hz}, 2 \mathrm{H}), 7.86$ $(\mathrm{s}, 1 \mathrm{H}), 7.53(\mathrm{~d}, J=8.3 \mathrm{~Hz}, 1 \mathrm{H}), 3.15(\mathrm{dd}, J=17.4,8.0 \mathrm{~Hz}, 1 \mathrm{H}), 2.94(\mathrm{dd}, J=17.4,3.8 \mathrm{~Hz}, 1 \mathrm{H}), 2.72(\mathrm{dt}$, $J=8.1,4.1 \mathrm{~Hz}, 1 \mathrm{H}), 2.43-2.33(\mathrm{~m}, 1 \mathrm{H}), 1.06(\mathrm{~d}, J=6.9 \mathrm{~Hz}, 3 \mathrm{H}), 0.79(\mathrm{~d}, J=6.8 \mathrm{~Hz}, 3 \mathrm{H}$; ESI-MS: $m / z$ $[\mathrm{M}+\mathrm{H}]^{+} 352$.

Methyl 4-((3-isopropoxy-2,3-dihydro-1H-inden-5-yl)carbamoyl) benzoate (35m). The title compound was prepared from $27 \mathbf{a}$ in a manner similar to that described for $35 \mathbf{a}$ as a pale yellow solid (91\%). m.p. 147 149 ${ }^{\circ} \mathrm{C}$; ${ }^{1} \mathrm{H}-\mathrm{NMR}$ : $\delta 8.16(\mathrm{dd}, J=8.2,4.4 \mathrm{~Hz}, 2 \mathrm{H}), 7.93(\mathrm{~d}, J=7.2 \mathrm{~Hz}, 2 \mathrm{H}), 7.73(\mathrm{~s}, 1 \mathrm{H}), 7.48(\mathrm{~d}$, $J=7.1 \mathrm{~Hz}, 1 \mathrm{H}), 7.23(\mathrm{~d}, J=8.2 \mathrm{~Hz}, 1 \mathrm{H}), 4.41(\mathrm{~d}, J=3.6 \mathrm{~Hz}, 1 \mathrm{H}), 3.96(\mathrm{~s}, 3 \mathrm{H}), 3.49(\mathrm{~s}, 3 \mathrm{H}), 3.25-3.17(\mathrm{~m}$, $1 \mathrm{H}), 2.57-2.50(\mathrm{~m}, 1 \mathrm{H}), 2.43(\mathrm{dd}, J=15.8,3.2 \mathrm{~Hz}, 1 \mathrm{H}), 1.17(\mathrm{~d}, J=7.0,3 \mathrm{H})$; ESI-MS: $m / z[\mathrm{M}+\mathrm{H}]^{+} 340$.

Methyl 4-((3-ethoxy-2-methyl-2, 3-dihydro-1H-inden-5-yl)carbamoyl) benzoate (35n). The title compound was prepared from $27 \mathbf{b}$ in a manner similar to that described for $35 \mathbf{a}$ as a pale yellow solid $(86 \%)$. m.p. 140 142 ${ }^{\circ} \mathrm{C} ;{ }^{1} \mathrm{H}-\mathrm{NMR}: \delta 8.16(\mathrm{~d}, J=8.2 \mathrm{~Hz}, 2 \mathrm{H}), 7.93(\mathrm{~d}, J=8.1 \mathrm{~Hz}, 2 \mathrm{H}), 7.82(\mathrm{~s}, 1 \mathrm{H}), 7.70(\mathrm{~s}, 1 \mathrm{H}), 7.46$ $(\mathrm{d}, J=7.4 \mathrm{~Hz}, 1 \mathrm{H}), 7.21(\mathrm{~d}, J=8.0 \mathrm{~Hz}, 1 \mathrm{H}), 4.49(\mathrm{~d}, J=4.6 \mathrm{~Hz}, 1 \mathrm{H}), 3.97(\mathrm{~s}, 3 \mathrm{H}), 3.71(\mathrm{q}, J=7.0 \mathrm{~Hz}, 2 \mathrm{H})$, $3.19(\mathrm{dd}, J=15.7,7.6 \mathrm{~Hz}, 1 \mathrm{H}), 2.57-2.45(\mathrm{~m}, 1 \mathrm{H}), 2.42(\mathrm{dd}, J=15.6,5.8 \mathrm{~Hz}, 1 \mathrm{H}), 1.27(\mathrm{t}, J=6.9 \mathrm{~Hz}, 3 \mathrm{H})$, $1.18(\mathrm{~d}, J=7.0 \mathrm{~Hz}, 3 \mathrm{H})$; ESI-MS: $m / z[\mathrm{M}+\mathrm{H}]^{+} 354$.

4-((2-Isopropyl-3-methoxy-2,3-dihydro-1H-inden-5-yl)carbamoyl) benzoate (35o). The title compound was prepared from $28 \mathbf{a}$ in a manner similar to that described for $35 \mathbf{a}$ as a pale yellow solid (87\%). m.p. 152 155 ${ }^{\circ} \mathrm{C} ;{ }^{1} \mathrm{H}-\mathrm{NMR}: \delta 8.16(\mathrm{~d}, J=8.3 \mathrm{~Hz}, 2 \mathrm{H}), 7.94(\mathrm{~d}, J=8.3 \mathrm{~Hz}, 2 \mathrm{H}), 7.89(\mathrm{~s}, 1 \mathrm{H}), 7.72(\mathrm{~s}, 1 \mathrm{H}), 7.48$ $(\mathrm{d}, J=7.8 \mathrm{~Hz}, 1 \mathrm{H}), 7.22(\mathrm{~d}, J=8.1 \mathrm{~Hz}, 1 \mathrm{H}), 4.70(\mathrm{~d}, J=5.0 \mathrm{~Hz}, 1 \mathrm{H}), 3.97(\mathrm{~s}, 3 \mathrm{H}), 3.48(\mathrm{~s}, 3 \mathrm{H}), 3.08(\mathrm{dd}$, 
$J=16.2,8.4 \mathrm{~Hz}, 1 \mathrm{H}), 2.60(\mathrm{dd}, J=16.2,6.3 \mathrm{~Hz}, 1 \mathrm{H}), 2.31(\mathrm{tt}, J=8.4,6.4 \mathrm{~Hz}, 1 \mathrm{H}), 1.84(\mathrm{dq}, J=13.4,6.7 \mathrm{~Hz}$, $1 \mathrm{H}), 1.00(\mathrm{~d}, J=6.8 \mathrm{~Hz}, 3 \mathrm{H}), 0.94(\mathrm{t}, J=7.4 \mathrm{~Hz}, 3 \mathrm{H})$; ESI-MS: $m / z[\mathrm{M}+\mathrm{H}]^{+} 368$.

Methyl 4-((3-ethoxy-2-isopropyl-2,3-dihydro-1H-inden-5-yl)carbamoyl) benzoate (35p). The title compound was prepared from $\mathbf{2 8 b}$ in a manner similar to that described for $\mathbf{3 5 a}$ as a pale yellow solid (97\%). m.p. 146 149 ${ }^{\circ} \mathrm{C} ;{ }^{1} \mathrm{H}-\mathrm{NMR}: \delta 8.15(\mathrm{~s}, 2 \mathrm{H}), 7.93(\mathrm{~d}, J=8.2 \mathrm{~Hz}, 2 \mathrm{H}), 7.74(\mathrm{~s}, 1 \mathrm{H}), 7.55(\mathrm{~s}, 1 \mathrm{H}), 7.17(\mathrm{~d}, J=7.9 \mathrm{~Hz}$, $1 \mathrm{H}), 4.56(\mathrm{~d}, J=5.0 \mathrm{~Hz}, 1 \mathrm{H}), 3.96(\mathrm{~s}, 3 \mathrm{H}), 3.00(\mathrm{q}, J=8.0 \mathrm{~Hz}, 2 \mathrm{H}), 2.68-2.58(\mathrm{~m}, 2 \mathrm{H}), 2.21-2.16(\mathrm{~m}, 1 \mathrm{H})$, 1.72-1.63 (m, 1H), $1.02(\mathrm{~d}, J=6.8 \mathrm{~Hz}, 3 \mathrm{H}), 0.98(\mathrm{~d}, J=6.6 \mathrm{~Hz}, 6 \mathrm{H})$; ESI-MS: $m / z[\mathrm{M}+\mathrm{H}]^{+} 368$.

4-((2,3-Dihydro-1H-inden-5-yl)carbamoyl) benzoate (35i). To a solution of 23 a (175 mg, $1.0 \mathrm{mmol})$ and Fe $(392 \mathrm{mg}, 7.0 \mathrm{mmol})$ in $\mathrm{EtOH}(20 \mathrm{~mL}), \mathrm{AcOH}(0.8 \mathrm{~mL})$ was added. The mixture was refluxing for $2 \mathrm{~h}$ under a nitrogen atmosphere at room temperature. Insoluble materials were removed by filtration and washed with EtOAc. The filtrate was evaporated to dryness under reduced pressure. The mixture was partitioned between water and EtOAc. The organic layer was washed with a saturated aqueous solution of brine, dried over anhydrous $\mathrm{Na}_{2} \mathrm{SO}_{4}$, and concentrated under vacuum. The residue 25a was used directly in the next reaction. To a solution of $33(150 \mathrm{mg}, 0.8 \mathrm{mmol})$ in thionyl chloride $(4 \mathrm{~mL})$, a drop of pyridine was added and refluxed for $24 \mathrm{~h}$. The thionyl chloride was removed by distillation and get 34 as pale yellow solid. To a solution of $25 \mathbf{a}(45 \mathrm{mg}, 0.3 \mathrm{mmol})$ in anhydrous pyridine $(2 \mathrm{~mL})$, 34 was added in $\mathrm{CH}_{2} \mathrm{Cl}_{2}(2 \mathrm{~mL})$ dropwise at $0{ }^{\circ} \mathrm{C}$. The mixture was stirred at room temperature for $7 \mathrm{~h}$ and then the methanol was removed by distillation. The organic layer was neutralized with $1 \mathrm{~N}$ $\mathrm{HCl}$. The mixture was partitioned between water and EtOAc. The organic layer was washed with a saturated aqueous solution of brine, dried over anhydrous $\mathrm{Na}_{2} \mathrm{SO}_{4}$, and concentrated under vacuum. The residue was purified by column chromatography on silica gel (eluent: hexane/EtOAc $=3 / 1$ ) to give $35 \mathrm{i}(77 \mathrm{mg}, 84 \%)$ as a pale yellow solid. m.p. $157 \sim 159{ }^{\circ} \mathrm{C} ;{ }^{1} \mathrm{H}-\mathrm{NMR}: \delta 8.15(\mathrm{~d}, J=8.4 \mathrm{~Hz}, 2 \mathrm{H}), 7.94$ $(\mathrm{d}, J=8.2 \mathrm{~Hz}, 2 \mathrm{H}), 7.83(\mathrm{~s}, 1 \mathrm{H}), 7.62(\mathrm{~s}, 1 \mathrm{H}), 7.34(\mathrm{~d}, J=7.9 \mathrm{~Hz}, 1 \mathrm{H}), 6.48(\mathrm{~s}, 1 \mathrm{H}), 3.96(\mathrm{~s}, 3 \mathrm{H}), 3.29(\mathrm{~s}$, 2H), 2.17 (s, 3H); ESI-MS: $m / z[\mathrm{M}+\mathrm{H}]^{+} 338$.

Methyl 4-((2-isopropyl-1H-inden-5-yl)carbamoyl) benzoate (35j). The title compound was prepared from 23b in a manner similar to that described for $35 \mathbf{i}$ as a pale yellow solid $(67 \%)$. m.p. $155 \sim 156{ }^{\circ} \mathrm{C}$; ${ }^{1} \mathrm{H}-\mathrm{NMR}: 88.16(\mathrm{~d}, J=8.4 \mathrm{~Hz}, 2 \mathrm{H}), 7.94(\mathrm{~d}, J=8.3 \mathrm{~Hz}, 2 \mathrm{H}), 7.78(\mathrm{~s}, 1 \mathrm{H}), 7.63(\mathrm{~s}, 1 \mathrm{H}), 7.35(\mathrm{~s}, 1 \mathrm{H}), 6.50(\mathrm{~s}$, $1 \mathrm{H}), 3.97(\mathrm{~s}, 3 \mathrm{H}), 3.34(\mathrm{~s}, 2 \mathrm{H}), 2.81-2.76(\mathrm{~m}, 1 \mathrm{H}), 1.24(\mathrm{~d}, J=6.8,3 \mathrm{H})$; ESI-MS: $m / z[\mathrm{M}+\mathrm{H}]^{+} 336$.

4-((2,3-Dihydro-1H-inden-5-yl)carbamoyl)benzoic acid (36a). To a solution of $35 \mathrm{a}$ (56 $\mathrm{mg}, 0.2 \mathrm{mmol}$ ) in $\mathrm{MeOH}(2 \mathrm{~mL}), 0.5 \mathrm{~N} \mathrm{LiOH}(0.4 \mathrm{~mL})$ was added dropwise at $0{ }^{\circ} \mathrm{C}$. The mixture was stirred at room temperature for $48 \mathrm{~h}$ and then neutralized with $1 \mathrm{~N} \mathrm{HCl}$. The $\mathrm{MeOH}$ was removed by distillation. After adding water $(10 \mathrm{~mL})$, the mixture was partitioned between water and EtOAc. The organic layer was washed with a saturated aqueous solution of brine, dried over anhydrous $\mathrm{Na}_{2} \mathrm{SO}_{4}$, and concentrated under vacuum. The residue was purified by column chromatography on silica gel (eluent: hexane $/ \mathrm{EtOAc} / \mathrm{AcOH}=30 / 10 / 1)$ to give $36 \mathrm{a}(52 \mathrm{mg}, 92 \%)$ as a white solid, purity: $97 \%$. m.p. $>250{ }^{\circ} \mathrm{C}$; ${ }^{1} \mathrm{H}-\mathrm{NMR}: \delta 13.26(\mathrm{~s}, 1 \mathrm{H}), 10.30(\mathrm{~s}, 1 \mathrm{H}), 8.14-7.92(\mathrm{~m}, 4 \mathrm{H}), 7.68(\mathrm{~s}, 1 \mathrm{H}), 7.47(\mathrm{~d}, J=8.0 \mathrm{~Hz}, 1 \mathrm{H}), 7.19(\mathrm{~d}$, $J=8.1 \mathrm{~Hz}, 1 \mathrm{H}), 2.93-2.76(\mathrm{~m}, 4 \mathrm{H}), 2.07-1.97(\mathrm{~m}, 2 \mathrm{H})$; ESI-MS: $m / z[\mathrm{M}-\mathrm{H}]^{-} 280$.

4-((3-Methoxy-2,3-dihydro-1H-inden-5-yl)carbamoyl)benzoic acid (36b). The title compound was prepared from $35 \mathbf{b}$ in a manner similar to that described for $36 \mathbf{a}$ as a white solid $(91 \%)$, purity: $96 \%$. m.p. $>250{ }^{\circ} \mathrm{C} ;{ }^{1} \mathrm{H}-\mathrm{NMR}: \delta 10.38(\mathrm{~s}, 1 \mathrm{H}), 8.15-8.01(\mathrm{~m}, 4 \mathrm{H}), 7.86(\mathrm{~s}, 1 \mathrm{H}), 7.63(\mathrm{~d}, J=8.1 \mathrm{~Hz}, 1 \mathrm{H}), 7.25(\mathrm{~d}$, $J=8.2 \mathrm{~Hz}, 1 \mathrm{H}), 4.86-4.72(\mathrm{~m}, 1 \mathrm{H}), 3.33(\mathrm{~s}, 3 \mathrm{H}), 3.00-2.87(\mathrm{~m}, 1 \mathrm{H}), 2.81-2.69(\mathrm{~m}, 1 \mathrm{H}), 2.36-2.32(\mathrm{~m}, 1 \mathrm{H})$, 1.99-1.93 (m, 1H); ESI-MS: $m / z$ [M - H] ${ }^{-} 310$. HRMS (ESI) calcd $[\mathrm{M}+\mathrm{H}]^{+}$for $\mathrm{C}_{18} \mathrm{H}_{18} \mathrm{NO}_{4} 312.1230$, found 312.1234 .

4-((3-Methoxy-2,3-dihydro-1H-inden-5-yl)carbamoyl)benzoic acid (36c). The title compound was prepared from $35 \mathrm{c}$ in a manner similar to that described for $36 \mathbf{a}$ as a white solid $(99 \%)$, purity: $95 \%$. m.p. $>250{ }^{\circ} \mathrm{C}$; ${ }^{1} \mathrm{H}-\mathrm{NMR}: \delta 10.37(\mathrm{~s}, 1 \mathrm{H}), 8.07-8.03(\mathrm{~m}, 4 \mathrm{H}), 7.81(\mathrm{~s}, 1 \mathrm{H}), 7.63(\mathrm{dd}, J=8.0,2.0 \mathrm{~Hz}, 1 \mathrm{H}), 7.23(\mathrm{~d}, J=8.2 \mathrm{~Hz}$, $1 \mathrm{H}), 4.89-4.83(\mathrm{~m}, 1 \mathrm{H}), 3.60-3.50(\mathrm{~m}, 2 \mathrm{H}), 2.94-2.88(\mathrm{~m}, 1 \mathrm{H}), 2.76-2.69(\mathrm{~m}, 1 \mathrm{H}), 2.36-2.30(\mathrm{~m}, 1 \mathrm{H})$, 
1.95-1.89 (m, 1H), $1.15(\mathrm{t}, J=7.0 \mathrm{~Hz}, 3 \mathrm{H})$; ESI-MS: $m / z[\mathrm{M}-\mathrm{H}]^{-}$324. HRMS (ESI) calcd $[\mathrm{M}+\mathrm{H}]^{+}$for $\mathrm{C}_{19} \mathrm{H}_{20} \mathrm{NO}_{4} 326.1387$, found 326.1392 .

4-((3-Isopropoxy-2,3-dihydro-1H-inden-5-yl)carbamoyl)benzoic acid (36d). The title compound was prepared from $35 \mathrm{~d}$ in a manner similar to that described for 36a as a white solid (97\%), purity: 97\%. m.p. $>250{ }^{\circ} \mathrm{C} ;{ }^{1} \mathrm{H}-\mathrm{NMR}: \delta 13.24(\mathrm{~s}, 1 \mathrm{H}), 10.36(\mathrm{~s}, 1 \mathrm{H}), 8.05(\mathrm{~s}, 4 \mathrm{H}), 7.74(\mathrm{~s}, 1 \mathrm{H}), 7.64(\mathrm{dd}, J=8.1$, $1.9 \mathrm{~Hz}, 1 \mathrm{H}), 7.21(\mathrm{~d}, J=8.2 \mathrm{~Hz}, 1 \mathrm{H}), 4.96(\mathrm{t}, J=6.1 \mathrm{~Hz}, 1 \mathrm{H}), 3.93-3.74(\mathrm{~m}, 2 \mathrm{H}), 3.85-3.79(\mathrm{~m}, 1 \mathrm{H})$, 2.94-2.84 (m, 1H), 2.73-2.67 (m, 1H), 2.40-2.34 (m, 1H), 1.87-1.81 (m, 1H), $1.17(\mathrm{~d}, J=6.0,3 \mathrm{H}), 1.16$ $(\mathrm{d}, J=6.5,3 \mathrm{H})$; ESI-MS: $m / z[\mathrm{M}-\mathrm{H}]^{-}$338. HRMS (ESI) calcd $[\mathrm{M}+\mathrm{H}]^{+}$for $\mathrm{C}_{20} \mathrm{H}_{22} \mathrm{NO}_{4} 340.1543$, found 340.1550 .

4-((3-Butoxy-2,3-dihydro-1H-inden-5-yl)carbamoyl)benzoic acid (36e). The title compound was prepared from 35e in a manner similar to that described for 36 a as a white solid $(90 \%)$. purity: $96 \%$. m.p. $>250{ }^{\circ} \mathrm{C} ;{ }^{1} \mathrm{H}-\mathrm{NMR}: \delta 13.26(\mathrm{~s}, 1 \mathrm{H}), 10.37(\mathrm{~s}, 1 \mathrm{H}), 8.05(\mathrm{~d}, J=2.1 \mathrm{~Hz}, 4 \mathrm{H}), 7.79(\mathrm{~s}, 1 \mathrm{H}), 7.63(\mathrm{dd}, J=8.0 \mathrm{~Hz}$, $1 \mathrm{H}), 7.21(\mathrm{~d}, J=8.0 \mathrm{~Hz}, 1 \mathrm{H}), 4.89-4.80(\mathrm{~m}, 1 \mathrm{H}), 3.51(\mathrm{td}, J=6.5,2.5 \mathrm{~Hz}, 2 \mathrm{H}), 2.98-2.85(\mathrm{~m}, 1 \mathrm{H}), 2.78-2.66$ $(\mathrm{m}, 1 \mathrm{H}), 2.38-2.30(\mathrm{~m}, 1 \mathrm{H}), 1.94-1.86(\mathrm{~m}, 1 \mathrm{H}), 1.56-1.42(\mathrm{~m}, 2 \mathrm{H}), 1.39-1.31(\mathrm{~m}, 2 \mathrm{H}), 0.88(\mathrm{t}, J=7.4 \mathrm{~Hz}$, 3H); ESI-MS: $m / z[\mathrm{M}-\mathrm{H}]^{-}$352. HRMS (ESI) calcd $[\mathrm{M}+\mathrm{H}]^{+}$for $\mathrm{C}_{21} \mathrm{H}_{24} \mathrm{NO}_{4} 354.1700$, found 354.1703.

4-((2-Methoxy-2,3-dihydro-1H-inden-5-yl)carbamoyl)benzoic acid (36f). The title compound was prepared from $35 \mathrm{f}$ in a manner similar to that described for $36 \mathrm{a}$ as a white solid $(86 \%)$, purity: $98 \%$. m.p. $>250{ }^{\circ} \mathrm{C}$; ${ }^{1} \mathrm{H}-\mathrm{NMR}: \delta 8.15(\mathrm{~d}, J=8.3 \mathrm{~Hz}, 2 \mathrm{H}), 7.92(\mathrm{~d}, J=8.2 \mathrm{~Hz}, 2 \mathrm{H}), 7.80(\mathrm{~s}, 1 \mathrm{H}), 7.62(\mathrm{~s}, 1 \mathrm{H}), 7.31(\mathrm{~d}, J=7.8 \mathrm{~Hz}$, $1 \mathrm{H}), 7.21(\mathrm{~d}, J=8.1 \mathrm{~Hz}, 1 \mathrm{H}), 4.31-4.23(\mathrm{~m}, 1 \mathrm{H}), 3.96(\mathrm{~s}, 3 \mathrm{H}), 3.38(\mathrm{~s}, 3 \mathrm{H}), 3.20-3.12(\mathrm{~m}, 2 \mathrm{H}), 3.03-2.94(\mathrm{~m}$, 2H); ESI-MS: $m / z[\mathrm{M}-\mathrm{H}]^{-}$310. HRMS (ESI) calcd $[\mathrm{M}+\mathrm{H}]^{+}$for $\mathrm{C}_{18} \mathrm{H}_{18} \mathrm{NO}_{4} 312.1230$, found 312.1240.

4-((2-Ethoxy-2,3-dihydro-1H-inden-5-yl)carbamoyl)benzoic acid (36g). The title compound was prepared from $35 \mathrm{~g}$ in a manner similar to that described for $36 \mathrm{a}$ as a white solid $(97 \%)$, purity: $97 \%$. m.p. $>250{ }^{\circ} \mathrm{C} ;{ }^{1} \mathrm{H}-\mathrm{NMR}: \delta 10.37(\mathrm{~s}, 1 \mathrm{H}), 8.12-8.01(\mathrm{~m}, 4 \mathrm{H}), 7.82(\mathrm{~s}, 1 \mathrm{H}), 7.65(\mathrm{dd}, J=8.1,1.7 \mathrm{~Hz}, 1 \mathrm{H}), 7.24(\mathrm{~d}$, $J=8.2 \mathrm{~Hz}, 1 \mathrm{H}), 4.94-4.80(\mathrm{~m}, 1 \mathrm{H}), 3.62-3.54(\mathrm{~m}, 2 \mathrm{H}), 2.97-2.88(\mathrm{~m}, 1 \mathrm{H}), 2.78-2.69(\mathrm{~m}, 1 \mathrm{H}), 2.37-2.31(\mathrm{~m}$, $1 \mathrm{H}), 1.98-1.90(\mathrm{~m}, 1 \mathrm{H}), 1.16(\mathrm{t}, J=7.0 \mathrm{~Hz}, 3 \mathrm{H})$; ESI-MS: $m / z[\mathrm{M}-\mathrm{H}]^{-} 324$. HRMS (ESI) calcd $[\mathrm{M}+\mathrm{H}]^{+}$ for $\mathrm{C}_{19} \mathrm{H}_{20} \mathrm{NO}_{4} 326.1387$, found 326.1396 .

4-((2-Isopropyl-2,3-dihydro-1H-inden-5-yl)carbamoyl)benzoic acid (36h). The title compound was prepared from $35 \mathrm{~h}$ in a manner similar to that described for $36 \mathrm{a}$ as a white solid $(94 \%)$, purity: $96 \%$. m.p. $>250{ }^{\circ} \mathrm{C} ;{ }^{1} \mathrm{H}-\mathrm{NMR}: \delta 8.07-8.02(\mathrm{~m}, 4 \mathrm{H}), 7.63(\mathrm{~s}, 1 \mathrm{H}), 7.47(\mathrm{~d}, J=7.9 \mathrm{~Hz}, 1 \mathrm{H}), 7.15(\mathrm{~d}, J=8.1 \mathrm{~Hz}, 1 \mathrm{H})$, 2.98-2.90 (m, 2H), 2.66-2.52 (m, 2H), 2.15-2.10 (m, 1H), 1.68-1.10 (m, 1H), $0.95(\mathrm{~d}, J=6.5 \mathrm{~Hz}, 3 \mathrm{H}), 0.94$ $(\mathrm{d}, J=6.5 \mathrm{~Hz}, 3 \mathrm{H})$; ESI-MS: $m / z$ [M $-\mathrm{H}]^{-}$322. HRMS (ESI) calcd $[\mathrm{M}+\mathrm{H}]^{+}$for $\mathrm{C}_{20} \mathrm{H}_{22} \mathrm{NO}_{3}$ 324.1594, found 324.1600 .

4-((2-Methyl-1H-inden-5-yl)carbamoyl)benzoic acid (36i). The title compound was prepared from 35i in a manner similar to that described for $36 \mathrm{a}$ as a white solid (98\%), purity: $95 \%$. m.p. $>250{ }^{\circ} \mathrm{C} ;{ }^{1} \mathrm{H}-\mathrm{NMR}$ : $10.31(\mathrm{~s}, 1 \mathrm{H}), 8.07-8.02(\mathrm{~m}, 4 \mathrm{H}), 7.78(\mathrm{~s}, 1 \mathrm{H}), 7.48(\mathrm{~d}, J=6.4 \mathrm{~Hz}, 1 \mathrm{H}), 7.26(\mathrm{~d}, J=8.1 \mathrm{~Hz}, 1 \mathrm{H}), 6.51(\mathrm{~s}$, $1 \mathrm{H}), 3.29(\mathrm{~s}, 2 \mathrm{H}), 2.12(\mathrm{~s}, 3 \mathrm{H})$; ESI-MS: $m / z[\mathrm{M}-\mathrm{H}]^{-}$292. HRMS (ESI) calcd $[\mathrm{M}+\mathrm{H}]^{+}$for $\mathrm{C}_{18} \mathrm{H}_{16} \mathrm{NO}_{3}$ 294.1125 , found 294.1129 .

4-((2-Isopropyl-1H-inden-5-yl)carbamoyl)benzoic acid (36j). The title compound was prepared from $35 \mathbf{j}$ in a manner similar to that described for $36 \mathrm{a}$ as a white solid $(83 \%)$, purity: $95 \%$. m.p. $>250{ }^{\circ} \mathrm{C} ;{ }^{1} \mathrm{H}-\mathrm{NMR}$ : $\delta 13.25(\mathrm{~s}, 1 \mathrm{H}), 10.34(\mathrm{~s}, 1 \mathrm{H}), 8.09-8.06(\mathrm{~m}, 4 \mathrm{H}), 7.72(\mathrm{~s}, 1 \mathrm{H}), 7.47(\mathrm{dd}, J=8.0,1.5 \mathrm{~Hz}, 1 \mathrm{H}), 7.35(\mathrm{~d}$, $J=8.1 \mathrm{~Hz}, 1 \mathrm{H}), 6.53(\mathrm{~s}, 1 \mathrm{H}), 3.37(\mathrm{~s}, 2 \mathrm{H}), 2.79-2.72(\mathrm{~m}, 1 \mathrm{H}), 1.20(\mathrm{~d}, J=6.5,3 \mathrm{H}), 1.19(\mathrm{~d}, J=6.5,3 \mathrm{H})$; ESI-MS: $m / z[\mathrm{M}-\mathrm{H}]^{-}$320. HRMS (ESI) calcd $[\mathrm{M}+\mathrm{H}]^{+}$for $\mathrm{C}_{20} \mathrm{H}_{20} \mathrm{NO}_{3} 322.1438$, found 322.1440 .

4-((2-Methyl-3-oxo-2,3-dihydro-1H-inden-5-yl)carbamoyl)benzoic acid (36k). The title compound was prepared from 35k in a manner similar to that described for 36a as a white solid (92\%), purity: 95\%. m.p. $>250{ }^{\circ} \mathrm{C}$ (AcOH-EtOAc-hexane); ${ }^{1} \mathrm{H}-\mathrm{NMR}: \delta 10.60(\mathrm{~s}, 1 \mathrm{H}), 8.09-8.04(\mathrm{~m}, 4 \mathrm{H}), 8.07(\mathrm{~d}, J=2.8 \mathrm{~Hz}$, $1 \mathrm{H}), 8.00(\mathrm{dd}, J=8.3,2.1 \mathrm{~Hz}, 1 \mathrm{H}), 7.56(\mathrm{~d}, J=8.4 \mathrm{~Hz}, 1 \mathrm{H}), 3.38-3.36(\mathrm{~m}, J=7.4 \mathrm{~Hz}, 1 \mathrm{H}), 2.78-2.72$ 
(m, 1H), 2.70-2.65 (m, 1H), $1.20(\mathrm{~d}, J=7.4 \mathrm{~Hz}, 3 \mathrm{H})$; ESI-MS: $m / z[\mathrm{M}-\mathrm{H}]^{-}$308. HRMS (ESI) calcd. $[\mathrm{M}+\mathrm{H}]^{+}$for $\mathrm{C}_{18} \mathrm{H}_{16} \mathrm{NO}_{4}$ 310.1074, found 310.1069.

4-((2-Isopropyl-3-oxo-2,3-dihydro-1H-inden-5-yl)carbamoyl)benzoic acid (361). The title compound was prepared from 351 in a manner similar to that described for 36a as a white solid (97\%), purity: $98 \%$. m.p. $>250{ }^{\circ} \mathrm{C} ;{ }^{1} \mathrm{H}-\mathrm{NMR}: \delta 13.30(\mathrm{~s}, 1 \mathrm{H}), 10.61(\mathrm{~s}, 1 \mathrm{H}), 8.14(\mathrm{~d}, J=1.8 \mathrm{~Hz}, 1 \mathrm{H}), 8.08(\mathrm{~d}, J=3.9 \mathrm{~Hz}, 4 \mathrm{H})$, $8.00(\mathrm{dd}, J=8.3,2.0 \mathrm{~Hz}, 1 \mathrm{H}), 7.60(\mathrm{~d}, J=8.3 \mathrm{~Hz}, 1 \mathrm{H}), 3.13(\mathrm{dd}, J=17.4,8.0 \mathrm{~Hz}, 1 \mathrm{H}), 2.88(\mathrm{dd}, J=17.5$, $3.8 \mathrm{~Hz}, 1 \mathrm{H}), 2.73(\mathrm{dt}, J=8.0,4.1 \mathrm{~Hz}, 1 \mathrm{H}), 2.30-2.24(\mathrm{~m}, 1 \mathrm{H}), 1.01(\mathrm{~d}, J=6.9 \mathrm{~Hz}, 3 \mathrm{H}), 0.74(\mathrm{~d}, J=6.8 \mathrm{~Hz}$, 3H); ESI-MS: $m / z[\mathrm{M}-\mathrm{H}]^{-}$336. HRMS (ESI) calcd $[\mathrm{M}+\mathrm{H}]^{+}$for $\mathrm{C}_{20} \mathrm{H}_{20} \mathrm{NO}_{4} 338.1387$, found 338.1384.

4-((3-Methoxy-2-methyl-2,3-dihydro-1H-inden-5-yl)carbamoyl)benzoic acid (36m). The title compound was prepared from $35 \mathrm{~m}$ in a manner similar to that described for 36a as a white solid (89\%), purity: 99\%. m.p. $>250{ }^{\circ} \mathrm{C}$ (AcOH-EtOAc-hexane); ${ }^{1} \mathrm{H}-\mathrm{NMR}: \delta 13.26(\mathrm{~s}, 1 \mathrm{H}), 10.36(\mathrm{~s}, 1 \mathrm{H}), 8.06-8.04(\mathrm{~m}, 4 \mathrm{H}), 7.84(\mathrm{~s}$, $1 \mathrm{H}), 7.63(\mathrm{dd}, J=8.1,1.8 \mathrm{~Hz}, 1 \mathrm{H}), 7.23(\mathrm{~d}, J=8.0,1 \mathrm{H}), 4.37(\mathrm{~d}, J=4.3 \mathrm{~Hz}, 1 \mathrm{H}), 3.40(\mathrm{~s}, 3 \mathrm{H}), 3.12-3.07$ $(\mathrm{m}, 1 \mathrm{H}), 2.45-2.34(\mathrm{~m}, 2 \mathrm{H}), 1.12(\mathrm{~d}, J=6.8 \mathrm{~Hz}, 3 \mathrm{H})$; ESI-MS: $m / z[\mathrm{M}-\mathrm{H}]^{-} 324$. HRMS (ESI) calcd $[\mathrm{M}+\mathrm{H}]^{+}$for $\mathrm{C}_{19} \mathrm{H}_{20} \mathrm{NO}_{4}$ 326.1387, found 326.1392.

4-((3-Ethoxy-2-methyl-2,3-dihydro-1H-inden-5-yl)carbamoyl)benzoic acid (36n). The title compound was prepared from $35 \mathrm{n}$ in a manner similar to that described for 36a as a white solid (97\%), purity: $98 \%$. m.p. $>250{ }^{\circ} \mathrm{C} ;{ }^{1} \mathrm{H}-\mathrm{NMR}: \delta 13.25(\mathrm{~s}, 1 \mathrm{H}), 10.36(\mathrm{~s}, 1 \mathrm{H}), 8.13-8.00(\mathrm{~m}, 4 \mathrm{H}), 7.80(\mathrm{~s}, 1 \mathrm{H}), 7.64(\mathrm{~d}, J=8.1 \mathrm{~Hz}$, $1 \mathrm{H}), 7.21(\mathrm{~d}, J=8.1 \mathrm{~Hz}, 1 \mathrm{H}), 4.44(\mathrm{~d}, J=4.5 \mathrm{~Hz}, 1 \mathrm{H}), 3.68(\mathrm{q}, J=7.0 \mathrm{~Hz}, 2 \mathrm{H}), 3.10-3.05(\mathrm{~m}, 1 \mathrm{H}), 2.40-3.34$ $(\mathrm{m}, 2 \mathrm{H}), 1.18(\mathrm{t}, J=7.0 \mathrm{~Hz}, 3 \mathrm{H}), 1.13(\mathrm{~d}, J=6.6 \mathrm{~Hz}, 3 \mathrm{H})$; ESI-MS: $m / z[\mathrm{M}-\mathrm{H}]^{-} 338$. HRMS (ESI) calcd $[\mathrm{M}+\mathrm{H}]^{+}$for $\mathrm{C}_{20} \mathrm{H}_{22} \mathrm{NO}_{4} 340.1543$, found 340.1549 .

4-((2-Isopropyl-3-methoxy-2,3-dihydro-1H-inden-5-yl)carbamoyl)benzoic acid (36o). The title compound was prepared from 35o in a manner similar to that described for 36a as a white solid (98\%), purity: $97 \%$. m.p. $>250{ }^{\circ} \mathrm{C} ;{ }^{1} \mathrm{H}-\mathrm{NMR}: \delta 13.21(\mathrm{~s}, 1 \mathrm{H}), 10.34(\mathrm{~s}, 1 \mathrm{H}), 8.10-8.02(\mathrm{~m}, 4 \mathrm{H}), 7.84(\mathrm{~s}, 1 \mathrm{H}), 7.64(\mathrm{dd}, J=8.5$, $1.5 \mathrm{~Hz}, 1 \mathrm{H}), 7.20(\mathrm{~d}, J=8.2 \mathrm{~Hz}, 1 \mathrm{H}), 4.65(\mathrm{~d}, J=3.3 \mathrm{~Hz}, 1 \mathrm{H}), 3.39(\mathrm{~s}, 3 \mathrm{H}), 3.01-2.96(\mathrm{~m}, 1 \mathrm{H}), 2.55-2.53$ (m, 1H), 2.23-2.15 (m, 1H), 1.83-1.76 (m, 1H), $0.95(\mathrm{~d}, J=6.7 \mathrm{~Hz}, 3 \mathrm{H}), 0.90(\mathrm{~d}, J=6.7 \mathrm{~Hz}, 3 \mathrm{H})$; ESI-MS: $m / z[\mathrm{M}-\mathrm{H}]^{-}$352. HRMS (ESI) calcd $[\mathrm{M}+\mathrm{H}]^{+}$for $\mathrm{C}_{21} \mathrm{H}_{24} \mathrm{NO}_{4} 354.1700$, found 354.1704.

4-((3-Ethoxy-2-isopropyl-2,3-dihydro-1H-inden-5-yl)carbamoyl)benzoic acid (36p). The title compound was prepared from $35 \mathrm{p}$ in a manner similar to that described for $36 \mathrm{a}$ as a white solid (98\%), purity: $98 \%$. m.p. $>250{ }^{\circ} \mathrm{C} ;{ }^{1} \mathrm{H}-\mathrm{NMR}: \delta 13.28(\mathrm{~s}, 1 \mathrm{H}), 10.36(\mathrm{~s}, 1 \mathrm{H}), 8.11-7.99(\mathrm{~m}, 4 \mathrm{H}), 7.80(\mathrm{~s}, 1 \mathrm{H}), 7.66-7.58(\mathrm{dd}$, $J=8.0,2.0 \mathrm{~Hz}, 1 \mathrm{H}), 7.18(\mathrm{~d}, J=8.2 \mathrm{~Hz}, 1 \mathrm{H}), 4.69(\mathrm{~d}, J=5.6 \mathrm{~Hz}, 1 \mathrm{H}), 3.72-3.57(\mathrm{~m}, 2 \mathrm{H}), 3.33-3.31(\mathrm{~m}, 1 \mathrm{H})$, $2.94(\mathrm{q}, J=8.4 \mathrm{~Hz}, 1 \mathrm{H}), 2.18-2.12(\mathrm{~m}, 1 \mathrm{H}), 1.81-1.76(\mathrm{~m}, 1 \mathrm{H}), 1.16(\mathrm{t}, J=7.0 \mathrm{~Hz}, 3 \mathrm{H}), 0.95(\mathrm{~d}, J=6.7 \mathrm{~Hz}$, $3 \mathrm{H}), 0.89(\mathrm{~d}, J=6.7 \mathrm{~Hz}, 3 \mathrm{H})$; ESI-MS: $m / z[\mathrm{M}-\mathrm{H}]^{-} 366$. HRMS (ESI) calcd $[\mathrm{M}+\mathrm{H}]^{+}$for $\mathrm{C}_{22} \mathrm{H}_{26} \mathrm{NO}_{4}$ 368.1856 , found 368.1863 .

\subsection{Biology}

\subsubsection{Receptor Binding Assay}

All synthesized compounds were tested for their binding affinity by using time resolved fluorescence resonance energy transfer (TR-FRET) assay, which used a LanthaScreen ${ }^{\circledR}$ TR-FRET RAR alpha Coactivator Assay Kit (Invitrogen, Carlsbad, CA, USA). Briefly, all experiments were performed in black 384-well low-volume plates (Corning Inc., Corning, NY, USA) in dark at room temperature. The final assay volume was $20 \mu \mathrm{L}$. All dilutions were made in assay buffer (TR-FRET Coregulator Buffer D). The final DMSO concentration was 1\%. A mixture of $5 \mathrm{nM}$ RAR alpha LBD-GST, $5 \mathrm{nM}$ TbAnti-GST antibody, $50 \mathrm{nM}$ Fluorescein-D22 was added to the wells. The only variable is the agonist concentration $\left(6.1 \times 10^{-11} \sim 1.0 \times 10^{-6} \mathrm{M}\right.$ final concentrations of each retinoid). The mixture was incubated for one hour in dark followed by fluorescence intensity determination on a SpectraMax M5 microplate reader (Molecular Devices Corporation, Sunnyvale, CA, USA) with $340 \mathrm{~nm}$ and 520 as excitation and emission wavelengths for terbium and 340 and 495 for fluorescein, respectively. 
Data were analyzed by using GraphPad Prism software (GraphPad Software, Inc., La Jolla, CA, USA) and FRET signal was determined for all treatments by dividing $520 \mathrm{~nm} / 495 \mathrm{~nm}$ signals. Graphs plotted as fold change of FRET signal for compounds treatment over DMSO only treatment.

\subsubsection{Inhibition of Cell Proliferation Assay}

Cells were seeded in 96-well plates (Corning Inc.) with a density of 2500 cells (NB4 or HL60) per well for overnight. Then, cells were exposed to each of the test compounds 36a-36p in gradient concentration of $10^{-9}, 10^{-8}, 10^{-7}, 10^{-6}, 10^{-5} \mathrm{~mol} / \mathrm{L}$. Control cultures were treated with the same volume of DMSO. After 72 hours of incubation, the cell density in each well were fixed by trichloroacetic acid and then measured using the SRB (sulforhodamine B) method. After rinsing, the SRB was solubilized in TrisHCl, and the optical density of each culture was determined with a Bio-Tek Elx 800 absorbance microplate reader (BioTek, Shoreline, WA, USA). The OD of the treated cultures was divided by that of the control cultures treated with solvent alone.

\subsubsection{Cell Differentiation Assay}

Cells $\left(1 \times 10^{6} / \mathrm{mL}\right)$ were treated with compounds at different concentrations based on $\mathrm{IC}_{50}$ in Table 2 for how long, temperature (provide the cell culture condition). After the treatment, cells were washed twice with PBS and then fixed with $75 \%$ alcohol overnight at $-20{ }^{\circ} \mathrm{C}$. The fixed cells were washed with PBS and blocked with $95 \mu \mathrm{L} \mathrm{3 \%} \mathrm{BSA} \mathrm{in} \mathrm{PBS} \mathrm{for} 45 \mathrm{~min}$ at room temperature. The cells were incubated with $5 \mu \mathrm{L} \mathrm{CD} 11 \mathrm{~b}-\mathrm{PE}$ at $4{ }^{\circ} \mathrm{C}$ for $45 \mathrm{~min}$ with protection from light. The antigens were then determined by a FACSCalibur flow cytometer (BD Biosciences Pharmingen, San Diego, CA, USA). The percentages of positive cells were quantitated using CellQuest Pro software. Cells stained with mouse IgG-PE served as negative controls. Both CD11b-PE and mouse IgG-PE antibodies were purchased from BD Biosciences. At least 10,000 cells were analyzed for each data point.

\section{Conclusions}

In summary, a series of mono-/di- substituted indene derivatives were designed and synthesized to explore the impact of the size of the hydrophobic region of ATRA derivatives on the bioactivity of related compounds. Binding, antiproliferative and cell differentiation assays showed that most of these compounds retained moderate $\operatorname{RAR} \alpha$ agonist activity and promising cell proliferation inhibitory activity. In particular, compound 36d with a high $\operatorname{RAR} \alpha$ binding affinity exhibited a strong ability to inhibit cell proliferation and to induce differentiation in NB4 cells. Structure and activity relationship study indicates that 2-alkylindene, 2-alkylindanone, or 1-alkoxyl-2-alkylindane are generally promising structural features for potent $\operatorname{RAR} \alpha$ agonists. All these results taken together demonstrate that indene as a promising start point for the development of novel RAR $\alpha$ agonists.

Acknowledgments: We thank Jianyang Pan (Pharmaceutical Informatics Institute, Zhejiang University) for performing the NMR spectrometry. We also appreciate national natural science foundation of China (81502914) for financial support.

Author Contributions: G.X., H.Y. and Y.H. conceived, designed and performed the experiments; L.P. and H.Q. performed the antiproliferative activity assay. Y.H. analyzed the data and drafted the manuscript.

Conflicts of Interest: The authors declare no conflict of interest.

\section{References}

1. Gronemeyer, H.; Gustafsson, J.A.; Laudet, V. Principles for modulation of the nuclear receptor s uperfamily. Nat. Rev. Drug Discov. 2004, 3, 950-964. [CrossRef] [PubMed]

2. De Lera, A.R.; Bourguet, W.; Altucci, L.; Gronemeyer, H. Design of selective nuclear receptor modulators: RAR and RXR as a case study. Nat. Rev. Drug Discov. 2007, 6, 811-820. [CrossRef] [PubMed]

3. Altucci, L.; Leibowitz, M.D.; Ogilvie, K.M.; de Lera, A.R.; Gronemeyer, H. RAR and RXR modulation in cancer and metabolic disease. Nat. Rev. Drug Discov. 2007, 6, 793-810. [CrossRef] [PubMed] 
4. De The, H.; Chen, Z. Acute promyelocytic leukaemia: Novel insights into the mechanisms of cure. Nat. Rev. Cancer 2010, 10, 775-783. [CrossRef] [PubMed]

5. Das, B.C.; Thapa, P.; Karki, R.; Das, S.; Mahapatra, S.; Liu, T.; Torregroza, I.; Wallace, D.P.; Kambhampati, S.; Veldhuizen, P.V. Retinoic acid signaling pathways in development and diseases. Bioorg. Med. Chem. 2014, 22, 673-683. [CrossRef] [PubMed]

6. Teng, M.; Duong, T.T.; Johnson, A.T.; Klein, E.S.; Wang, L.M.; Khalifa, B.; Chandraratna, R.A.S. Identification of highly potent retinoic acid receptor alpha-selective antagonists. J. Med. Chem. 1997, 40, 2445-2451. [CrossRef] [PubMed]

7. Kagechika, H. Novel synthetic retinoids and separation of the pleiotropic retinoidal activities. Curr. Med. Chem. 2002, 9, 591-608. [CrossRef] [PubMed]

8. Kagechika, H.; Shudo, K. Synthetic retinoids: Recent developments concerning structure and clinical utility. J. Med. Chem. 2005, 48, 5875-5883. [CrossRef] [PubMed]

9. Ostrowski, J.; Roalsvig, T.; Hammer, L.; Marinier, A.; Starrett, J.E.; Yuo, K.L.; Reczek, P.R. Serine 232 and methionine 272 define the ligand binding pocket in retinoic acid receptor subtypes. J. Biol. Chem. 1998, 273, 3490-3495. [CrossRef] [PubMed]

10. Zusi, F.C.; Lorenzi, M.V.; Vivat-Hannah, V. Selective retinoids and rexinoids in cancer therapy and chemoprevention. Drug Discov. Today 2002, 7, 1165-1174. [CrossRef]

11. Anonymous. Tamibarotene: AM 80, retinobenzoic acid, Tamibaro. Drugs RED 2004, 5, 359-362.

12. Takeshita, A.; Shibata, Y.; Shinjo, K.; Yanagi, M.; Tobita, T.; Ohnishi, K.; Miyawaki, S.; Shudo, K.; Ohno, R. Successful treatment of relapse of acute promyelocytic leukemia with a new synthetic retinoid, Tamibarotene. Ann. Intern. Med. 1996, 124, 893-896. [CrossRef] [PubMed]

13. Takeuchi, M.; Yano, T.; Omoto, E.; Takahashi, K.; Kibata, M.; Shudo, K.; Harada, M.; Ueda, R.; Ohno, R. Relapsed acute promyelocytic leukemia previously treated with all-trans retinoic acid: Clinical experience with a new synthetic retinoid, Am-80. Leuk. Lymphoma 1998, 31, 441-451. [CrossRef] [PubMed]

14. Barluenga, J.; Alonsocires, L.; Campos, P.J.; Asensio, G. Mercury(ii) oxide tetrafluoroboric acid; enhanced alkylating ability of alkyl bromides-A general-synthesis of alcohols and ethers. Synthesis 1983, 1983, 53-55. [CrossRef]

15. Barluenga, J.; Alonsocires, L.; Asensio, G. Mercury(ii) oxide tetrafluoroboric acid-A new reagent in organic-synthesis; A convenient diamination of olefins. Synthesis 1979, 1979, 962-964. [CrossRef]

16. Merisor, E.; Conrad, J.; Malakar, C.; Beifuss, U. Unexpected Lewis Acid Mediated Reactions of 1-Arylbut-3-en-1-ols with Trimethyl Orthoformate-A New Synthesis of Homoallyl Ethers and Chlorides. Synlett 2008, 2008, 903-907. [CrossRef]

17. Lanotte, M.; Martinthouvenin, V.; Najman, S.; Balerini, P.; Valensi, F.; Berger, R. NB4, a maturation inducible cell-line with $\mathrm{t}(15-17)$ marker isolated from a human acute promyelocytic leukemia (M3). Blood 1991, 77, 1080-1086. [PubMed]

18. Altucci, L.; Gronemeyer, H. The promise of retinoids to fight against cancer. Nat. Rev. Cancer 2001, 1, 181-193. [CrossRef] [PubMed]

Sample Availability: Samples of the compounds are available from the authors.

(C) 2016 by the authors; licensee MDPI, Basel, Switzerland. This article is an open access article distributed under the terms and conditions of the Creative Commons Attribution (CC-BY) license (http://creativecommons.org/licenses/by/4.0/). 